ISSN: 0514-7336

DOI: http://dx.doi.org/10.14201/zephyrus2018817191

\title{
EL POBLADO FORTIFICADO METALÚRGICO DEL CALCOLÍTICO MEDIO Y FINAL DE PUENTE DE SANTA BÁRBARA (HUÉRCAL-OVERA, ALMERÍA)
}

\section{The fortified metallurgical settlement from the Middle-Late Chalcolithic in Puente de Santa Bárbara (Huércal-Overa, Almería)}

Pedro González Quintero*, Alfredo Mederos Martín**, Antonio Díaz Cantón***, Charles Bashore Acero****, Jorge Chamón Fernández $^{* * * * *}$ y Marco A. Moreno Benítez ${ }^{* * * * * *}$

* Dpto. de Ciencias Históricas-UlPGC. Edificio de Humanidades. Plaza de la Constitución, s/n. 35003 Las Palmas de Gran Canaria. Correo-e: pgonzalez@dch.ulpgc.es.ID ORCID:0000-0002-4632-5009

** Dpto. de Prehistoria y Arqueología-UAM. Facultad de Filosofía y Letras. Campus de Cantoblanco. 28049 Madrid. Correo-e: alfredo.mederos@uam.es.ID ORCID:0000-0002-0036-7940

*** Univ. de Almería. Cl Lope de Vega, 8, 1.․ A. Edificio La Almunia. 04003 Almería.

Correo-e: dressel20@hotmail.com.ID ORCID:0000-0002-7403-2553

**** Dpto. de Prehistoria y Arqueología. Facultad de Filosofía y Letras-UGR. Campus Universitario de Cartuja. 18071 Granada. Correo-e: charlesbashoreadero@gmail.com. ID ORCID: 0000-0001-6161-1997

***** Dpto. de Física-Quimica. Centro Tecnológico AIMEN. Edificio A. Priegue. C/ Relva, 27. 36410 Pontevedra. Correo-e: jorge.chamon@aimen.es. ID ORCID:0000-0002-8092-7150

***** Tibicena Arqueología y Patrimonio SLC. Cl Obispo Rabadán, 41 Bajo. 35003 Las Palmas de Gran Canaria. Correo-e: tibicena@tibicena.com. ID ORCID:0000-0002-5840-111X

Recepción: 31/05/2017; Revisión: 4/11/2017; Aceptación: 20/1/2018

Resumen: El poblado fortificado calcolítico de Puente de Santa Bárbara (Huércal-Overa, Almería), de 1,5 ha, está situado a $3 \mathrm{~km}$ de las minas de cobre de Cerro Minado, explotadas al menos durante el Calcolítico Final, y presenta mineral en bruto, escorias parcialmente procesadas y nodulillos de cobre. Un 4\% de todos los fragmentos cerámicos corresponde a fragmentos de vasijas de reducción y crisoles, distribuidos espacialmente por los tres sectores excavados del yacimiento y sugieren la generalización de la metalurgia dentro del hábitat. El porcentaje de evidencias metalúrgicas solo podría equipararse en el sudeste de la Península Ibérica a los poblados calcolíticos de Parazuelos (Lorca, Murcia) y Agua Amarga (Lorca, Murcia), otro pequeńo poblado de 0,25 ha. Estos datos permiten plantear la hipótesis de si ya en el Calcolítico Final pudieron surgir en el sudeste de la Península Ibérica pequeños asentamientos especializados en la producción de útiles o pequeños lingotes metálicos elaborados en crisoles rectangulares.

Palabras clave: Sureste ibérico; Edad del Cobre; Campaniforme; metalurgia; análisis microespacial.

Авsтract: The fortified chalcolithic settlement in Puente de Santa Bárbara (Huércal-Overa, Almería), with $1.5 \mathrm{ha}$, located $3 \mathrm{~km}$ away from the Cerro Minado copper mines, and exploited at least during the Late Chalcolithic, presents copper ores, crucible smelting and melting debris such as slags, casting prills, reduction vessels and crucibles. $4 \%$ of all the ceramic fragments correspond to reduction vessel and crucible fragments,

(C) Universidad de Salamanca

Zephyrus, LXXXI, enero-junio 2018, 71-91 
spatially distributed in the three excavated sectors and suggest the generalization of the metallurgy within the habitat. The percentage of metallurgical evidences could only be compared in the southeast of the Iberian Peninsula to the Copper Age settlements of Parazuelos (Lorca, Murcia) and Agua Amarga (Lorca, Murcia), another minor site of 0.25 ha. These data suggest the hypothesis of small settlements specialized in the production of tools or small metallic ingots made in rectangular crucibles during the Late Chalcolithic in the Southeast of the Iberian Peninsula.

Key words: Southeast Iberia; Copper Age; Bell Beaker; metallurgy; micro-spatial analysis.

\section{Introducción ${ }^{1}$}

La metalurgia ha sido considerada uno de los elementos fundamentales en los cambios sociales y políticos que acontecieron en el III y II milenios a. C. en la Península Ibérica no solo por el desarrollo tecnológico, sino por lo que ha supuesto desde una visión de cambio de las estructuras de poder, emergencia de la desigualdad social e incluso como un elemento fundamental en el desarrollo de la guerra (Lull et al., 2010b).

El metal de cobre era posible rentabilizarlo al máximo, bien cuando se produjese una fragmentación o desgaste de la pieza, bien cuando hubiese un cambio tecnológico o estilístico, al poder ser refundido, adquiriendo de nuevo valor socioeconómico dentro de la sociedad, lo que explica su rápida aceptación.

En el sudeste de la Península Ibérica se plantea tradicionalmente que los inicios de la metalurgia están asociados a la Edad del Cobre y, específicamente, a la denominada 'Cultura de Los Millares', en un momento cronológico que se iniciaría en torno al $3100 \mathrm{cal}$ AC.

No obstante, a partir de los datos aportados por las excavaciones en el Cerro Virtud (Herrerías, Cuevas del Almanzora, Almería), con la aparición de un pequeño fragmento de vasija de reducción con restos de escoria adherida en el nivel c del corte B2 (Ruiz Taboada y Montero, 1999: 210, fig. 5; Montero, 1999: 335-336, fig. 2), no podemos descartar, como también defienden Rovira y Ambert (2002: 108), que en un momento anterior, durante la transición del Neolítico Medio (Montero et al.,

${ }^{1}$ Queremos agradecer la participación durante la excavación de E. Aramburu Escolano, J. López Salmerón, E. Chávez Álvarez y M. ${ }^{a}$ M. Ruiz-Gómez de Fez.
1999: 127) a inicios del Neolítico Final, 4900-4500 cal AC (Mederos, 1995: 83 tab.), pudiera ya haberse iniciado la explotación puntual de este recurso metalúrgico (Montero y Rovira, 2001: 33; Rovira, 2004: 10-11) en zonas inmediatas a mineralizaciones con óxidos de cobre. Incluso se llega a plantear, como sucedió en otras áreas geográficas del Mediterráneo, la posibilidad de un origen autóctono para la invención de la metalurgia (Montero, 1999: 336337; Rovira, 2004: 11; Montero y Murillo, 2014: $68,73)$. Sin embargo, sería deseable confirmar en otros yacimientos actividades metalúrgicas con una cronología tan antigua.

Los primeros restos que aparecen asociados a este momento de inicios del Neolítico Final parecen corroborar la hipótesis de que el mineral cuprífero utilizado procedía de los filones cercanos al yacimiento en Herrerías y que se utilizaban vasijas cerámicas para la reducción del mineral. De tal manera que los hornos cerrados no serían utilizados en los primeros momentos de la metalurgia en la Península Ibérica, al no identificarse resto alguno relacionado con estas estructuras. Por el contrario, se reconocen en los yacimientos estructuras de tendencia circular con restos abundantes de cenizas donde se desarrollaron actividades relacionadas con la transformación del mineral.

\section{El yacimiento de Puente de Santa Bárbara}

El yacimiento de Puente de Santa Bárbara se encuentra ubicado en el término municipal de Huércal-Overa, al n de la provincia de Almería, entre los límites naturales de la depresión prelitoral murciana y la cuenca de Vera, a una altitud sobre el nivel del mar de $221 \mathrm{~m}$ (Fig. 1). 


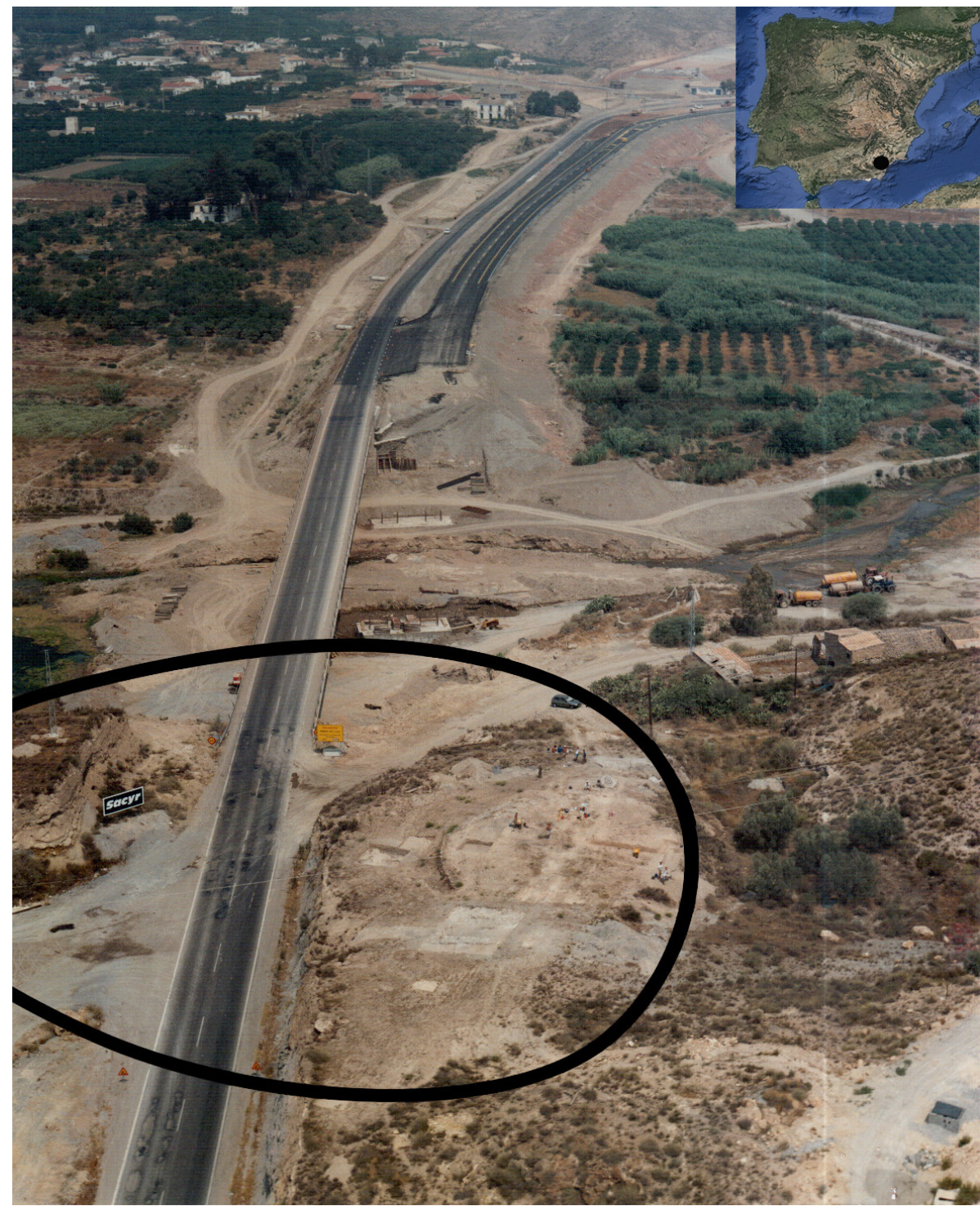

FIG. 1. Vista general del yacimiento y la afección de la construcción de la autovia sobre el mismo.

Su emplazamiento, en un espolón amesetado orientado al noroeste, sobre el cauce del río Almanzora, característico de los asentamientos de la Edad del Cobre, permite plantear un control en la comunicación entre la depresión de Vera con el valle del alto río Almanzora que conecta hacia el Oeste con la Hoya de Guadix-Baza.

Para la reconstrucción paleoambiental del entorno del asentamiento durante la segunda mitad del III milenio cal AC, el estudio antracológico de 104 muestras de carbones identificó 13 taxones, donde las especies mayoritarias eran el acebuche-Olea europaea var. sylvestris con el $37,57 \%$ y el lentisco/ cornicabra-Pistacia lentiscus o Pistacia sp. con el $19,22 \%$, que indican un matorral denso, acompañado de encina/coscoja-Quercus ilex-coccifera con el 8,65\%, sauce-Salix sp. con el $7,69 \%$ de la rivera fluvial y pino carrasco-Pinus halepensis con un 4,80\% (Rodríguez Ariza, 1998: 283, gráf. 53), procedente de la inmediata Sierra Almagro.

Las primeras referencias al asentamiento fueron el resultado de las prospecciones arqueológicas que dirigimos durante el año 1990 (González Quintero et al., 1992), dentro del marco general del proyecto de investigación Los inicios de la metalurgia en la cuenca del rio Almanzora ${ }^{2}$.

La excavación arqueológica se planteó con unos objetivos muy concretos como consecuencia del trazado de la autovía de Puerto Lumbreras-Almería, que iba a afectar a una parte del yacimiento, aunque con anterioridad ya había quedado cortado por la mitad cuando se produjo la construcción de la carretera nacional N-340 de Almería a Murcia (González Quintero et al., 1993). En principio, se

2 Proyecto aprobado y subvencionado por la Dirección General de Bienes Culturales de la Junta de Andalucía: codirigido por M. ${ }^{a}$ D. Camalich Massieu y D. Martín Socas. 
trataba de valorar el impacto que las diferentes actuaciones antrópicas habían repercutido en el yacimiento, incluyendo la que iba a afectarle con la nueva autovía, al mismo tiempo que nos permitiría conocer su extensión y restos estructurales que parecían identificarse en superficie.

Si tratamos de considerar las variables que inciden en el emplazamiento del yacimiento del Puente de Santa Bárbara, estas se presentan relativamente nítidas. Desde un punto de vista subsistencial se ubica inmediato a una extensa área con suelos de la clase IIIs según el Mapa de Cultivos y Aprovechamientos de España del Ministerio de Agricultura, capaces de soportar laboreo de forma permanente, aun cuando existen factores limitantes como la pedregosidad y la escasa profundidad, disponiéndose dichos suelos a ambas márgenes del río, tanto en dirección a La Concepción, como entre Santa Bárbara y Overa.

El bajo porcentaje de vegetación de ripisilva que nos indica el análisis antracológico, como la presencia de sauce-Salix sp., álamo-Populus sp., taray-Tamarix sp. o la ausencia de fresno-Fraxinus sp., sugiere que los bordes del cauce fluvial del río Almanzora estaban siendo utilizados para actividades agrícolas (Rodríguez Ariza, 1998: 281).

El abastecimiento de agua permanente está garantizado por la presencia del río Almanzora, que justamente traza un meandro coincidiendo con la ladera occidental del yacimiento, lo que reduce la velocidad de la corriente y facilita una potencial captación del mismo, inclusive en periodos de estío, pues se produce su estancamiento en dicha zona.

Respecto a las rutas de comunicación, su papel estratégico se advierte por la continuada reutilización del área inmediata desde el Neolítico hasta época hispanomusulmana. Su presencia en un nudo de tres vías naturales de comunicación así lo evidencia, que podríamos ejemplificar en el propio río Almanzora o eje o/E-E/o, justo en las denominadas Bocas del Almanzora; el Pasillo del Pozo de la Cuesta o eje septentrional que, procedente de la depresión lorquina, atraviesa la Sierra Almagro sirviéndose de la Rambla de Santa Bárbara y desemboca a poco más de $500 \mathrm{~m}$ del mismo; y el Pasillo de Ballabona o eje meridional, hoy aprovechado por la N-340, que pone en contacto las vías restantes de comunicación con la Depresión de Vera. Un desplazamiento poblacional durante la Edad del Bronce de unos 600-700 m, hacia el Cerro de San Miguel en esta última dirección (Siret y Siret, 1890: 137), aprovechando las mejores posibilidades defensivas de dicho emplazamiento, apoya la continuidad en el control de este nudo de comunicaciones.

\section{Los trabajos arqueológicos}

Durante la campaña de prospección arqueológica que realizamos en 1990, se documentó, entre otros, el yacimiento de Puente de Santa Bárbara, que parecía tener gran importancia tanto en lo que respecta a su ubicación geográfica -estratégica y agrícola- como en relación a su organización interna - defensa y manufactura metalúrgica-. Los restos artefactuales identificados en superficie permitían plantear un espacio destinado a la manufactura metalúrgica, destacando la gran cantidad de fragmentos cerámicos y un número considerable de nódulos de escorias de cobre, así como la presencia de lienzos de muro que parecían definir un espacio defensivo (González Quintero et al., 1992: 62).

Tras dos campañas de excavación en abril y julio-agosto de 1991, se constató que se trataba de un asentamiento fortificado, con al menos un bastión semicircular, en torno al cual se había desarrollado una actividad económica destinada al tratamiento del mineral de cobre y donde, con toda probabilidad, se llevaba a cabo la manufactura de los artefactos de cobre.

La hipótesis metalúrgica se vio refrendada al documentarse, en sus inmediaciones, áreas de aprovisionamiento de la materia prima para la manufactura metalúrgica. Así, a unos $3 \mathrm{~km}$ en línea recta, tras atravesar el río Almanzora en dirección NE, se encuentra la mina del Cerro Minado, también conocida como Cuesta Alta o Cena del Depósito, que ha estado en producción hasta los años $50 \mathrm{del}$ s. Xx, donde existen los óxidos de cobre, en vetas recubiertas de 
malaquita y cuprita, entre muchos otros (Delgado et al., 2014: 16-20; Favreau et al., 2013) $)^{3}$.

El Cerro Minado sería principalmente un área de extracción de mineral de cobre, donde destacan, entre otros, los minerales de cobre como la malaquita $-\mathrm{Cu}_{2} \mathrm{CO}_{3}(\mathrm{OH})_{2}-$ o la cuprita $-\mathrm{Cu}_{2} \mathrm{O}-$. Se trata de una explotación primero en galería y después en cantera, donde se han identificado algunos picos de mineros que corresponden a las fases más antiguas de su explotación.

Domergue (1987: 14) mencionaba el Cerro Minado en su catálogo de minas antiguas en la Península Ibérica, atribuyéndole varias mazas de minero en diorita con ranura, aunque la información es indirecta y le fue facilitada por J. P. Jacquin. El yacimiento fue prospectado por Montero, quien en su tesis doctoral ${ }^{4}$ localizó carbonatos de cobre en un sustrato rocoso de dolomías. Su última concesión minera vigente fue en 1900 para una superficie de 12 ha en la denominada 'Cena del Depósito', colindante a 'El Recuerdo de mi Padre', concedida en 1905, que solo presenta una galería de $10 \mathrm{~m}$ de longitud (Escanilla, 2016: 116, 118-119, tab. 3.9).

Más recientemente, Delgado et al. (2014: 24-25, figs. 5-6; Escanilla y Delgado, 2015: 85-88, tab. 1) publican la presencia de varios picos y percutores en el Cerro Minado o Cena del Depósito. Su relación con el proceso de la extracción del material cuprífero, podemos plantearla al presentar algunas de las piezas restos de adherencias de color verde de malaquita o azul de la azurita sobre fracturas por percusión de las superficies activas de los artefactos (Delgado et al., 2014: 26-27). La cronología aportada de $3905 \pm 21$ вр (Delgado et al., 2014: 30) o 2469-2336 cal AC -2 o, Calib 7.0.4- para esta mina, inicios del Calcolítico Final, confirma que durante la segunda mitad del III milenio estaba en producción.

3 Cf. la p. 154 de Montero Ruiz, I.: Estudio arqueometalúrgico en el Sudeste de la Península Ibérica. Tesis doctoral defendida en 1992 en la Univ. Complutense de Madrid (disponible en http://webs.ucm.es/BUCM/tesis/19911996/H/0/ AH0000301.pdf).

4 Op. cit. n. 3: 150-154.

\section{Estructuras documentadas}

En la excavación el objetivo básico era conocer el grado de deterioro que había sufrido el yacimiento y su posible secuencia estratigráfica. Para ello, se realizaron varias catas arqueológicas que pusieron al descubierto un conjunto arqueológico significativo que nos obligó, dada la importancia que estaba adquiriendo a nivel estructural y artefactual, a realizar una excavación en área abierta que nos permitiera conocer la organización interna del poblado y su distribución (Fig. 2).

El trabajo arqueológico fue realizado ateniéndonos a las normas metodológicas de cualquier excavación arqueológica mediante un control estricto de los hallazgos, que nos permitiera disponer de una documentación cualificada. Para ello, se procedió a una excavación siguiendo las unidades sedimentarias con un registro individualizado, tridimensional y posicional -orientación, postura, etc.- de artefactos y ecofactos. Se utilizó un sistema mediante fichas de registro que permitiera la necesaria identificación y localización espacial tridimensional de los restos arqueológicos, así como la definición de los contextos sedimentarios y estructurales.

El registro se individualizó desde el mismo corte, salvo los restos procedentes de la criba, que se procesaba en conjunto, pero siempre dentro de su unidad sedimentaria. Al mismo tiempo, la excavación fue apoyada por sistemas de registro con soportes gráficos y fotográficos a diversas escalas y con capacidad de ser transferidas a bases de datos cuantitativas que nos permitieran poder llevar a cabo una reconstrucción del yacimiento una vez excavado.

Los resultados de la excavación permitieron poner al descubierto una estructura defensiva que parece rodear el yacimiento (Fig. 3), aunque, al haber sufrido diferentes alteraciones, solo hemos podido documentarla en dos sectores. Ahora bien, atendiendo a los restos conservados, se trataba de una estructura elaborada con la misma técnica y aparejo que las realizadas en otros yacimientos contemporáneos, caso, por ejemplo, del poblado de Zájara (Cuevas del Almanzora, Almería) (Camalich et al., 


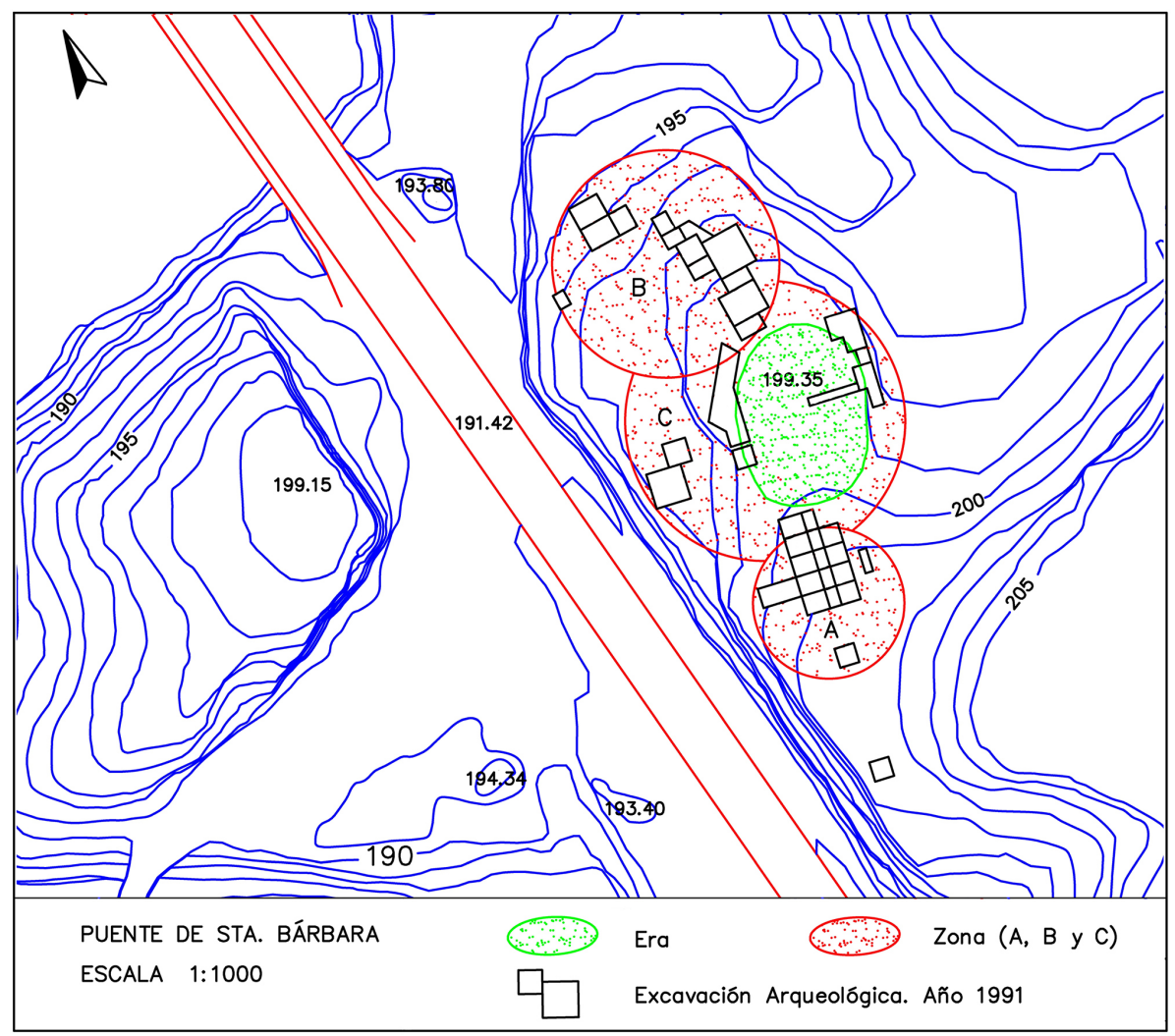

FIG. 2. Topografía y planimetría del yacimiento.

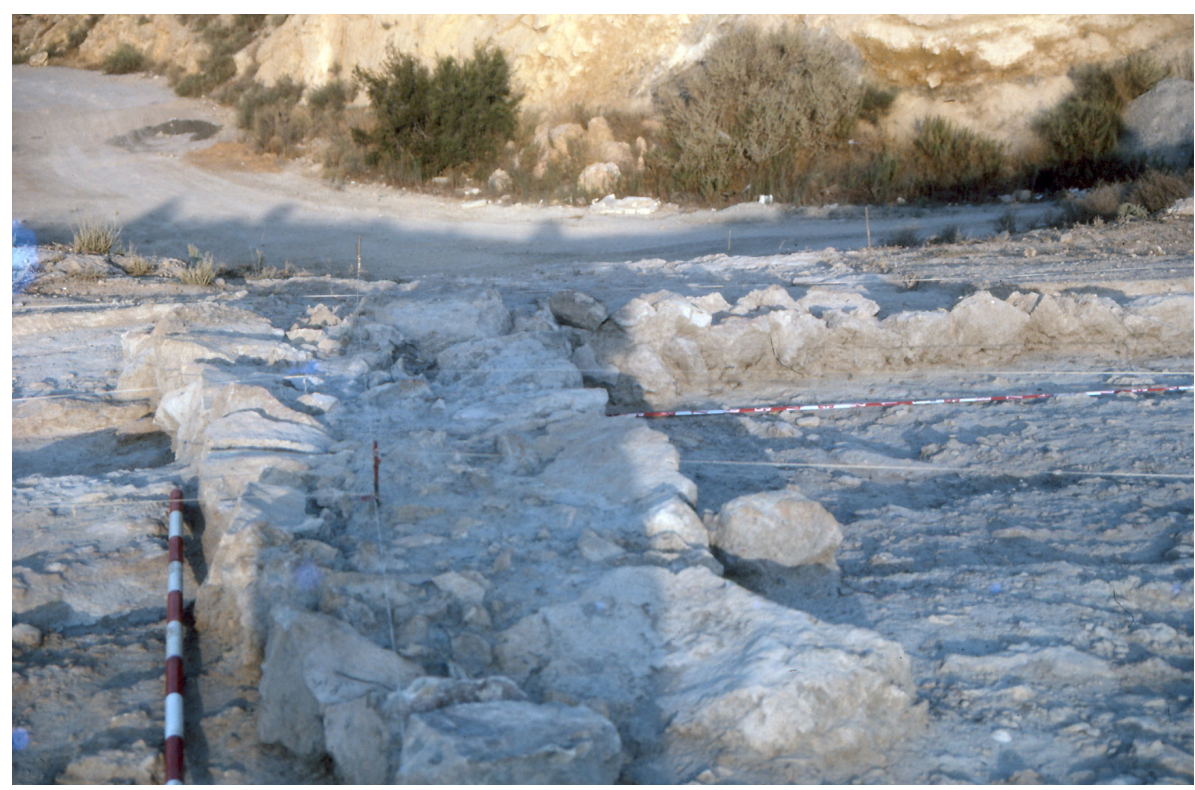

FIG. 3. Parte de la estructura defensiva que rodea el yacimiento.

(Arribas et al., 1987; Molina González y Arribas, 1993: 315). Es decir, se conservaban dos hiladas de piedras de dimensiones medianas y grandes que estaban encajonadas sobre el suelo originario del cerro aprovechando en ocasiones las oquedades del mismo para embutir las piedras y, en otros casos, reutilizando la propia base del espigón para levantar la primera hilada del muro. El interior del lienzo se encontraba relleno de piedras de pequeñas dimensiones con tierra que le servía de argamasa para cohesionar toda la estructura. Hemos de mencionar que únicamente pudo detectarse la primera hilada o la base de cimiento de la misma, como consecuencia de varios fenómenos. En primer lugar, la propia erosión del medio, tan activa en esta zona del sudeste de la Península Ibérica y, en segundo lugar, otra aún más perjudicial, como fue la acción antrópica que a principios del pasado siglo transformó parte de la estructura originaria del espolón mediante la construcción de una era y la carretera.

Estas modificaciones 1992: 206-207, lám. 2), o el conocido yacimiento de Los Millares (Santa Fe de Mondújar, Almería) afectaron a un área importante del yacimiento. La construcción en su parte central, aprovechando el 
rellano que existía en el cerro, de una era de aproximadamente 25 m de diámetro (Figs. 1 y 2) provocó la ruptura y desaparición de una gran parte de la muralla y del área interior del asentamiento. También la acción antrópica se dejó sentir en la reutilización de los elementos constitutivos de la muralla -piedras e, inclusive, algún molino- para plantear los muros sobre los que apoyar la mencionada era. Igualmente, una gran parte de las piedras sirvieron para formar muros de contención y terraplenar zonas colindantes a la ladera $\mathrm{E}$, destinadas al cultivo.

Esta destrucción de gran parte del yacimiento nos impidió, por tanto, obtener una visión más global del mismo, que tendría una superficie aproximada de 1,5 ha, si incluimos la parte que fue arrasada por la carretera N-340, que une Almería con Murcia. El desarrollo estratigráfico en el área excavada presentó varios aspectos que debemos tener en cuenta. En primer lugar, la potencia máxima fue de $60 \mathrm{~cm}$ en torno al espacio que se encuentra asociado a una parte de la estructura defensiva (Fig. 10), mientras que en la zona donde se encuentran el bastión y el resto de la muralla no alcanza los $10 \mathrm{~cm}$ (Fig. 11).

No obstante, se pudo detectar, además del mencionado lienzo de muro, otra estructura, de características similares a la anterior, aunque de menor grosor y con piedras más pequeñas, que se encontraba al interior y adosada a la misma y con la presencia de vasijas de reducción, crisoles y nódulos de escorias, además de elementos cerámicos e instrumentos líticos pulimentados.

En uno de los extremos del espolón se documentó otra parte de la muralla, a la que se le adosó un bastión circular con su acceso (Fig. 4). Dicho bastión había sido instalado en uno de los extremos del espolón justamente donde la muralla inicia un giro para ir bordeándolo, sobre el cauce de una pequeña

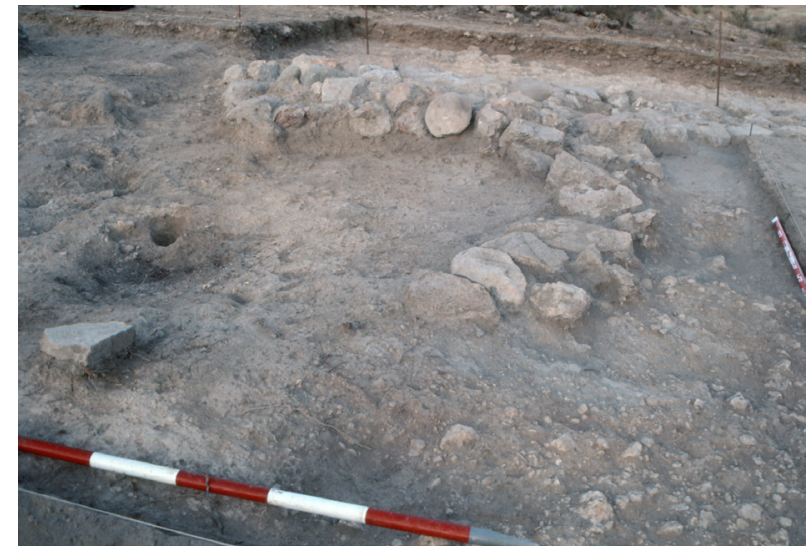

FIG. 4. Bastión circular anexo a la muralla.

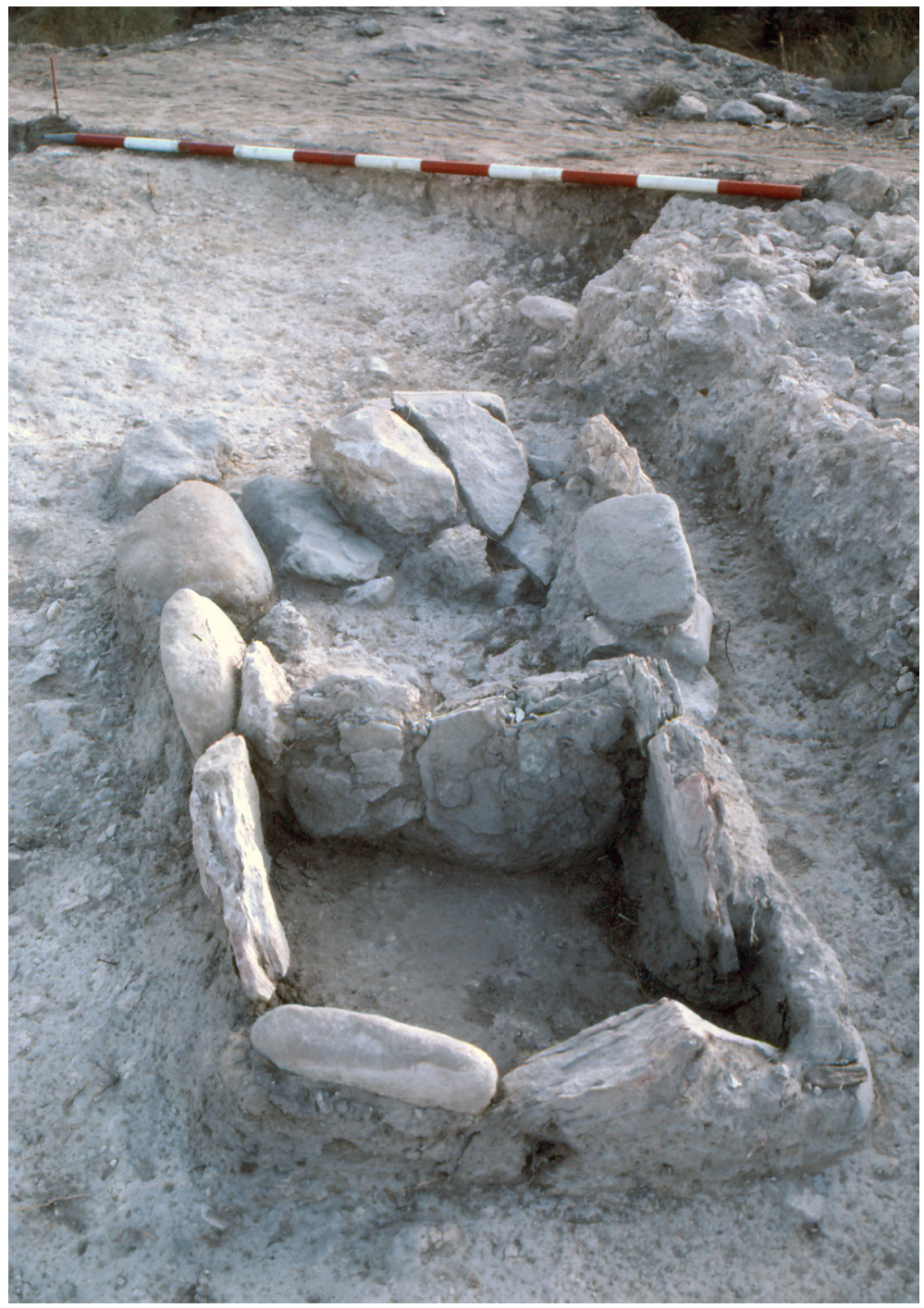

FIG. 5. Estructura rectangular asociada a un molino. 


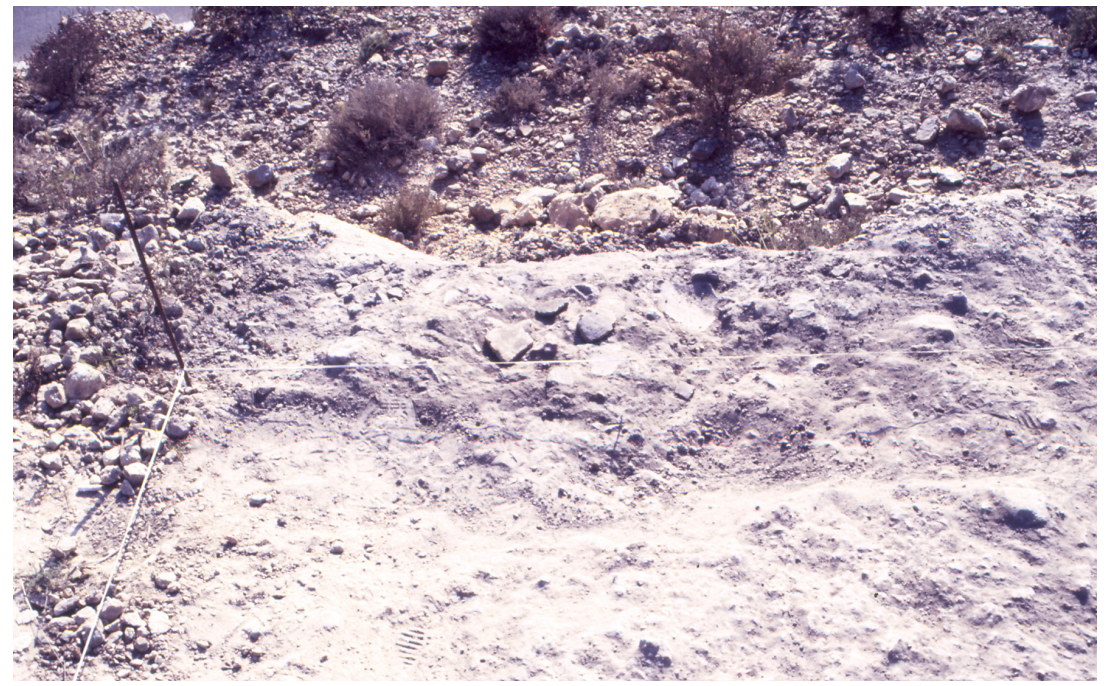

FIG. 6. Estructura seccionada por la construcción de la antigua carretera N-340 con las paredes termoalteradas.

vaguada que bordea al poblado por el Este, la cual va a desembocar en el río Almanzora. Realizado con la misma técnica constructiva anteriormente comentada, aunque muy afectada su cara externa por la erosión, presentaba anexos al muro unos huecos de tendencia circular que interpretamos como agujeros para hincar postes de madera que sostendrían una posible techumbre.

$\mathrm{Al}$ interior de la muralla, y cerca de la ubicación del bastión, se documentan unos alineamientos de piedras, en esta ocasión hincadas verticalmente, conformando una doble estructura rectangular de reducidas dimensiones (Fig. 5). Se trata de una cubeta, de fines no del todo claros, si bien mantenía una cierta similitud con otras relacionadas con actividades productivas relacionadas con la molturación del grano. Esta hipótesis estaría apoyada por la presencia, junto a dicha estructura, de un molino con su respectiva muela. Sin embargo, en el interior de la cubeta no se observó presencia alguna de dicha actividad de molturación, mientras que en su exterior aparecieron subproductos de la reducción de cobre como fragmentos de cerámicas con adherencias, tanto de vasijas de reducción como de crisoles y escorias, con lo que es posible que el molino estuviera dedicado a triturar las escorias para recuperar los nódulos de cobre antes de introducirlos en los crisoles de fundición.
En este sentido, conocemos en el poblado de Valencina de la Concepción (Sevilla), molinos destinados a la trituración de las escorias en la estructura 182 del sector IV (Nocete et al., 2008: 723-724, fig. 6), y también se han documentado en la propia mina de Cerro Minado (Escanilla, 2016: 127, fig. 3.47)5. En estos molinos debía de triturarse la masa de escoria obtenida en las vasijas de reducción para proceder a la recuperación de las pequeñas bolitas de cobre en los nódulos de escoria -slag prillspara introducirlas en un crisol de fundición, por lo que se separaban fragmentos de escoria para una segunda reducción en los crisoles.

Esta cubeta presentaba adosada otra, pero con unos matices estructurales diferenciales. Pues si la primera presentaba unas piedras o lajas hincadas, la segunda, aunque formando parte de la misma estructura, estaba construida con piedras de mayor grosor y disposición más irregular, dando la apariencia de un cuerpo macizo.

Otra estructura muy interesante, lamentablemente seccionada por el perfil de la carretera, está excavada en el sustrato rocoso, con las paredes termoalteradas (Fig. 6). Pudo ser donde se fundía el mineral dentro de una vasija de reducción, similar a otra que ha sido interpretada como un horno en el yacimiento calcolítico de Valencina de la Concepción, la estructura IEs 14 (Nocete et al., 2008: 724-725, fig. 7). No obstante, en su interior no se documentaron vasijas de reducción alguna. Estudios experimentales como los realizados por Rovira muestran que utilizando un crisol pequeño basta con una cubeta de $15 \mathrm{~cm}$ de diámetro y $15 \mathrm{~cm}$ de profundidad excavada en el suelo, o bien de $30 \mathrm{~cm}$ de diámetro y $30 \mathrm{~cm}$ de profundidad (Rovira, 1999: 106 y 2005: 92-93, fig. 5).

5 Escanilla Artigas, N.: Recursos minerales de cobre y su explotación prehistórica en el Sudeste peninsular: el Valle del Guadalentin (Murcia). Tesis doctoral defendida en 1996 en la Univ. Autónoma de Barcelona. 


\section{Registro arqueológico}

La cerámica es el material arqueológico predominante en el yacimiento, como es habitual en estas etapas arqueológicas, en el que podemos diferenciar dos grandes grupos. Uno, asociado con tareas metalúrgicas y un segundo conjunto cerámico que, en principio, no parece estar relacionado con dichos trabajos. Las piezas presentan formas abiertas con un acabado donde predominan las superficies alisadas, si bien los porcentajes son diferentes si se trata del interior o del exterior. La decoración es muy escasa, apenas 10 fragmentos que suponen el 0,128\% de la cerámica del yacimiento, con una decoración mediante incisiones y/o impresiones formando motivos campaniformes, simbólicos y cordones en relieve. Lo mismo sucede con los elementos de sujeción que solo suponen el 0,05\% del total de la cerámica.

Entre la cerámica decorada podemos resaltar la presencia de un vaso campaniforme muy pequeño con una decoración incisa en una franja ancha, habitual pero tosca en su elaboración, que presenta como elemento más llamativo la existencia de una carena muy baja y la ausencia de decoración en la base, lo que no es frecuente (Fig. 7).

Además cabe mencionar cuernecillos de arcilla que apuntan a actividades textiles como los localizados en El Malagón (Cúllar, Granada) (Arribas et al., 1978: 84-85, fig. 13, lám. 10a-b), además de piedras de pizarra de forma circular y perforadas

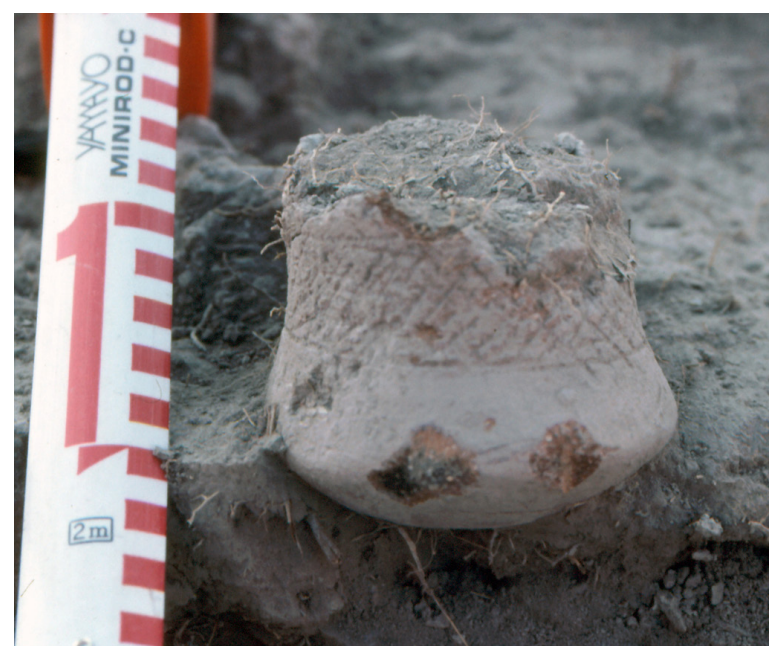

FIG. 7. Vaso campaniforme localizado durante la excavación.

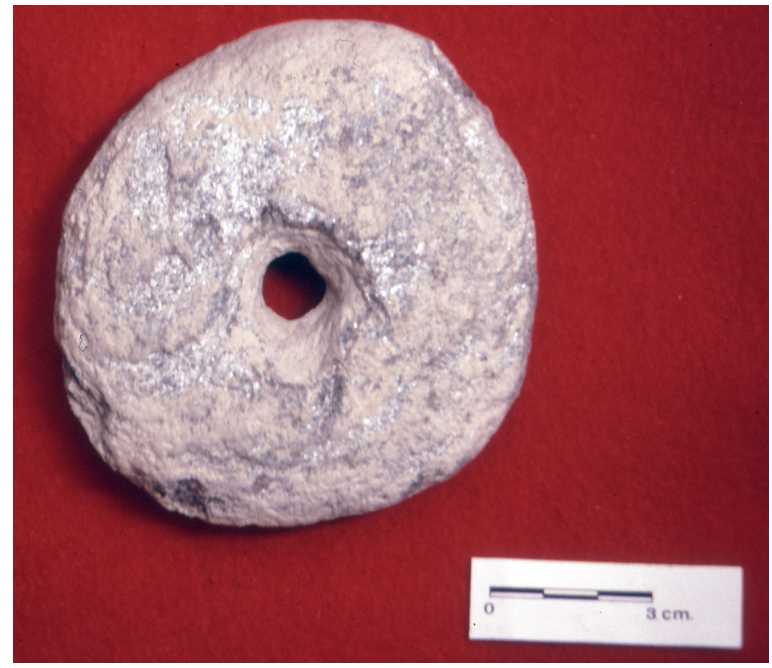

FIG. 8. Piedra circular de pizarra con perforación central.

por el centro que pudieron también estar relacionadas con las anteriores como fusayolas, que también conocemos en el mismo poblado (Arribas et al., 1978: 86-87, fig. 14j) o en otros de la Edad del Bronce como Peñalosa (Moreno et al., 2012: 104, fig. 2/2) (Fig. 8).

Dos puntas de flecha de sílex, una de base cóncava y otra de aletas y pedúnculo, además un número considerable de restos de talla de sílex, quizás resultado de una modificación secundaria de los soportes obtenidos en el área fuente ${ }^{6}$. Podrían vincularse a actividades defensivas dentro del poblado, tal como sucede en la cabaña viı del fortín 1 de Los Millares (Ramos, 1986) o las puntas de flecha en proceso de fabricación del fortín 7 de Los Millares (Molina, 1991: 213). Por último, molinos de mano que, como hemos mencionado, además de su función en actividades subsistenciales, podrían están relacionados con la trituración de las escorias de cobre.

\subsection{Distribución espacial de las evidencias metalúrgicas}

La presencia de numerosos fragmentos de vasijas de cerámica de medio y gran tamaño que presentan

6 Afonso Marrero, J. A.: Aspectos técnicos de la producción lítica de la prehistoria reciente de la alta Andalucia y el Sureste. Tesis doctoral defendida en 1993 en la Univ. de Granada (microfichas). 
en su cara interna adherencias de escoria tradicionalmente relacionadas con la metalurgia del cobre (Rovira y Ambert: 2002) ha permitido plantear que la reducción de los minerales de cobre se producía habitualmente en las vasijas cerámicas, los verdaderos contenedores utilizados para la reducción. En consecuencia, debemos atribuir a estas cerámicas un papel fundamental que, en proporciones considerables, aparecen en este yacimiento del Puente de Santa Bárbara (Fig. 9).

En este sentido, hemos constatado que al menos un 4\% -316 piezas o fragmentos- de la cerámica del yacimiento presenta restos de haber sido utilizada como contenedor para la

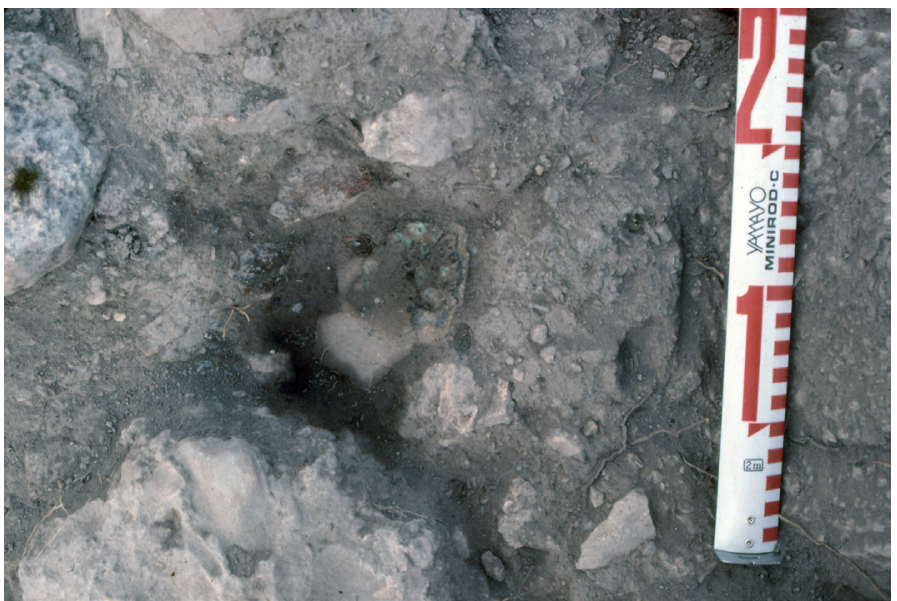

Fig. 9. Fragmento cerámico de vasija de reducción con restos de mineral. reducción o para la fundición. Si a ello unimos la gran cantidad de nódulos de escorias, restos de mineral y fragmentos de materias primas utilizadas en el proceso, estamos ante un yacimiento muy representativo de los momentos avanzados de la Edad del

para otros yacimientos de la Edad del Cobre y del Bronce (Müller et al., 2007; Nocete, 2004; Cortes, 2007: 65).

Por otro lado, atendiendo a la distribución microespacial de los conjuntos cerámicos y su relación

Cobre en Almería, cuyo emplazamiento y funcionalidad debió de estar vinculada con unos fines concretos como un centro especializado de transformación metalúrgica.

Las vasijas de reducción son aquellas piezas que mediante la combustión son utilizadas para reducir el mineral de cobre, mientras que en los crisoles se realiza, generalmente, la fusión del metal. Ahora bien, no podemos descartar que estos crisoles también hayan sido utilizados para la reducción del mineral, e incluso que puedan haber sido utilizados como 'moldes', formando pequeñas tortas de metal de cobre, tal como se plantea

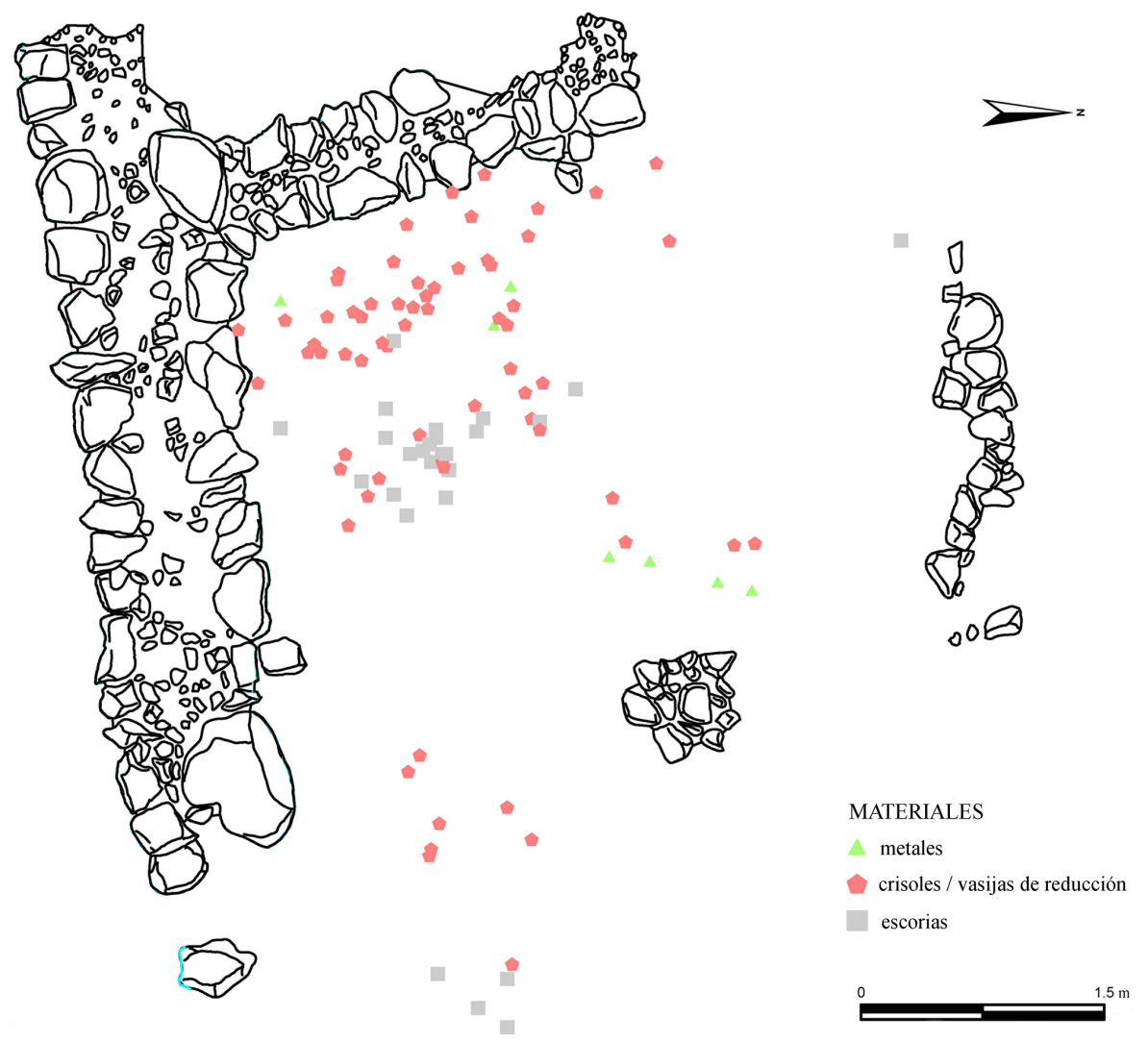

Fig. 10. Distribución de material metalúrgico en el área de la muralla. 
con las unidades sedimentarias del yacimiento, no se observa una clara diferenciación o separación de las tareas desarrolladas, sino su generalización por todo el yacimiento (Figs. 10 y 11).

No obstante, una gran parte de los crisoles, vasijas de reducción, restos de metal y escorias se encuentran en el espacio que hemos denominado zona A, que supone el $27,5 \%$ de la superficie excavada, donde creemos que se desarrollaba la mayor parte de las tareas de transformación del mineral de cobre, llegando a suponer el 34,5\% del total de los registros identificados durante la excavación (Fig. 2).

Un 30,3\% se identificó en la zona B, que representa el 37,1\% del área excavada, donde se delimitó el cierre de la estructura defensiva con el bastión y el resto, un $35,2 \%$, en la zona c, que se corresponde con el área más afectada por la construcción de la era y que debió corresponderse con un espacio en el que la actividad metalúrgica debió ser una continuidad de la desarrollada en la zona A, y que supone el $35,4 \%$ del total excavado. Tanto las vasijas de reducción, como los crisoles, presentan una pasta de calidad media y desgrasantes finos y medios, aunque en muchos casos también aparecen los gruesos, pero en un número inferior que los demás. En este poblado la pasta es limo-arcillosa, con un acabado de sus superficies interiores algo mejores que las exteriores, normalmente groseras.

La mayoría de las vasijas cerámicas destinadas a la reducción de minerales de cobre son piezas que generalmente tienen una superficie grosera, en algún caso alisada, poseen formas de tendencia semiesférica o de casquete esférico, con la boca muy abierta y un fondo plano. No obstante, dado el procedimiento para extraer el material, lo que nos encontramos en el yacimiento son fragmentos cerámicos informes, como consecuencia de la ruptura de la pieza para desprender la amalgama de nódulos de escoria y metal de la misma. Ello explicaría el alto grado de fragmentación de estas vasijas

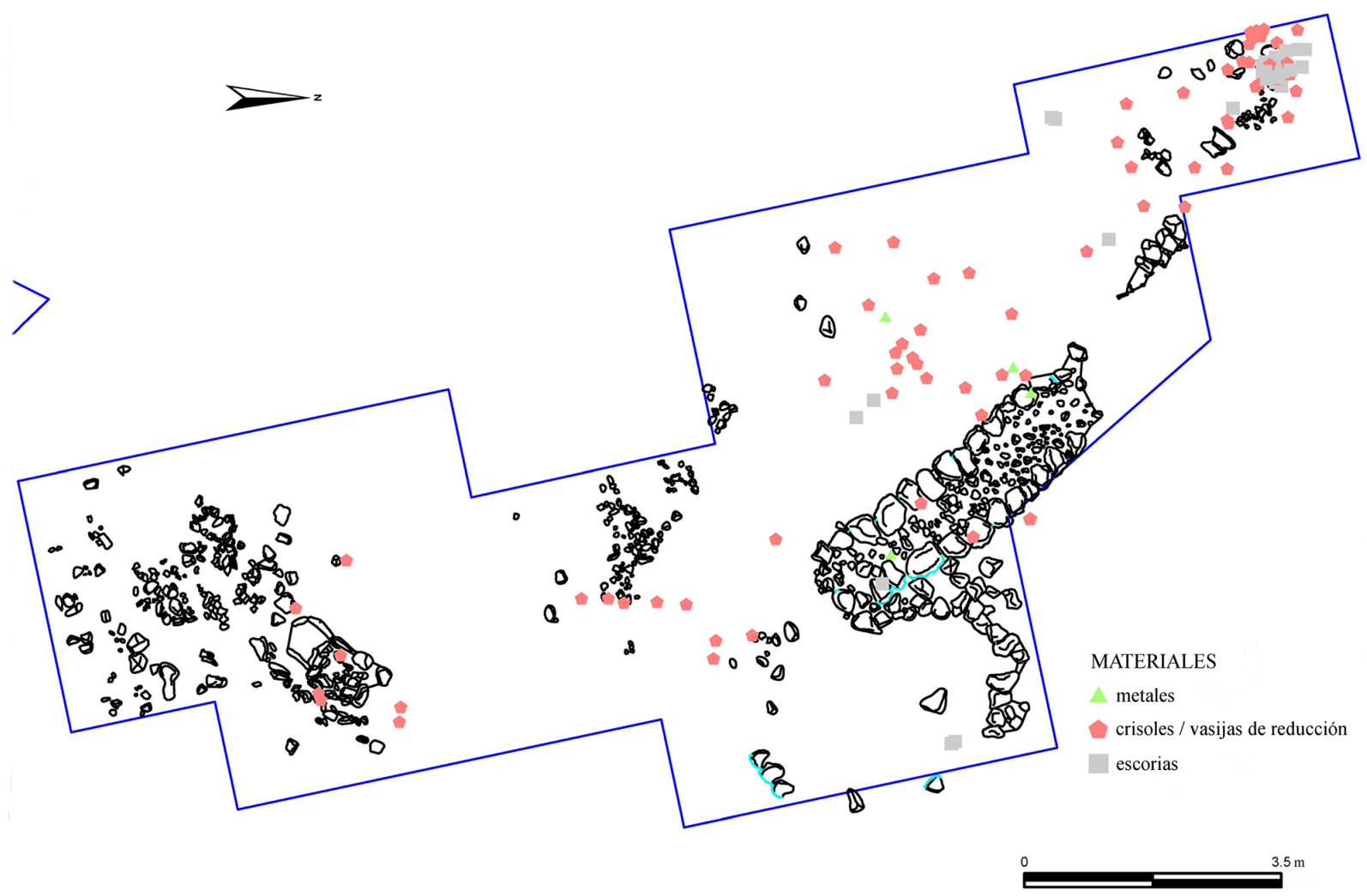

Fig. 11. Distribución de material metalúrgico en el área del bastión junto a la muralla y de la estructura rectangular asociada con un molino. 


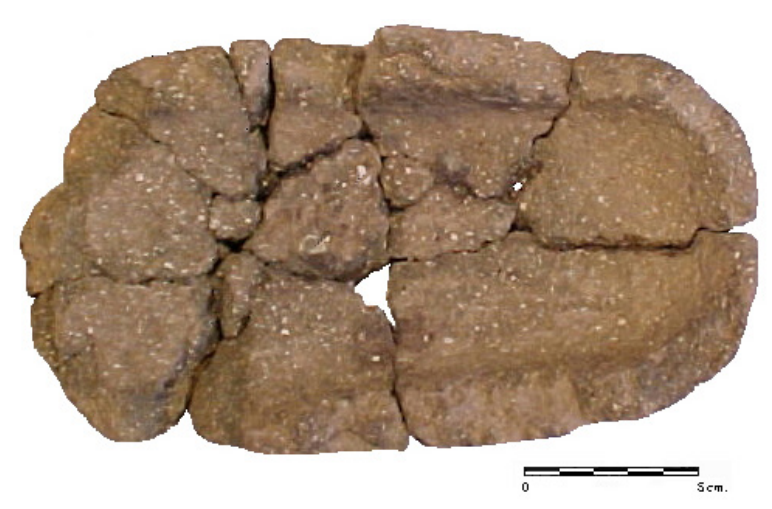

FIG. 12. Crisol rectangular.

y, además, nos ha imposibilitado determinar el número mínimo de piezas registradas.

Crisoles rectangulares con extremos redondeados como el del corte 16 con unas dimensiones de 21,7 $\mathrm{x} 11,8 \times 3,8 \mathrm{~cm}$, presentando una cubeta interior de $19,9 \times 8,2 \times 2,2 \mathrm{~cm}$ (Fig. 12), los encontramos en El Malagón (Cúllar, Granada), con base plana y evidencias de haber sido sometido a altas temperaturas (Arribas et al., 1978: 84, fig. 12d)7. Una pieza entera se recuperó en las excavaciones de Siret en Almizaraque, actualmente expuesta en el Museo Arqueológico Nacional -MAN-. Otro ejemplar completo procede de Las Pilas (Mojácar, Almería), de c. 27 × $6 \mathrm{~cm}$ (Montero, 1999: 340; Murillo et al., 2017: 3, 5 fig. 3 h; 12, 26, fig. 18), mientras que la reducción y fusión del mineral se realizaría en vasijas de reducción, normalmente formas abiertas de tipo plato o cazuela, pero también cuencos hemiesféricos, que suelen encontrarse en estado muy fragmentario, como el ejemplar reconstruido de La Ciñuela (Mazarrón, Murcia) (Montero, 1999: 344, fig. 5), que presenta la característica capa escorificada en su superficie interior, también expuesto en el MAN.

\section{Análisis arqueometalúrgicos}

Se han estudiado varios restos metalúrgicos procedentes tanto del yacimiento de Santa Bárbara

Cf. p. 307, fig. 2 y p. 311, fig. 9 de Moreno Onorato, M. ${ }^{a}$ A.: El Malagón. Un asentamiento de la Edad del Cobre en el altiplano de Cúllar-Chirivel. Tesis doctoral defendida en 1993 en la Univ. de Granada (microfichas). como de restos minerales recogidos en la cima de Cerro Minado (Huércal-Overa). En total se han analizado 3 restos de vasija de reducción, 6 muestras minerales y 1 goterón de fundición mediante fluorescencia de rayos-X -FRX-. En el caso de minerales los análisis se realizaron sobre los puntos con mayor concentración mineral y no sobre zonas de impregnaciones. Dichos análisis se realizaron en el Museo Arqueológico Nacional usando una pistola de FRX portátil INNOV-X Alpha en modo de medición para metales. Los tiempos de adquisición de los espectros se fijaron en 40 segundos. El equipo fue previamente calibrado para el análisis de metales. Los valores cuantitativos son corregidos con el método de parámetros fundamentales - por software con patrones virtuales-. El ánodo empleado es de Ag por lo que el límite de detección de la plata -Ag- y el antimonio - $\mathrm{Sb}$ - es del 0,20\%, mientras que para el resto de elementos se sitúa en un $0,02 \%$. Los resultados obtenidos pueden observarse en las Figs. 13 y 14.

En cuanto a los minerales se refiere, a simple vista se vuelve a constatar la alta variabilidad de las mineralizaciones del Cerro Minado, ya indicado en estudios anteriores (Montero, 1994: 151-153, tabs.; Delgado et al., 2014: 28, tab. 3; Escanilla, 2016: 131-132, tab. 3.12). Los resultados indican la presencia de mineralizaciones complejas de carácter polimetálico, siendo las fases minerales más abundantes malaquita y cuprita. Cabe destacar la correlación $\mathrm{Cu}$-As documentada en varias muestras, siendo los elementos mayoritarios -especialmente en el caso de las muestras Cerro Minado sB sn 3, 4 y 5-, alcanzando el 29,8\% de As en el caso 3. Sin embargo, es de especial interés el nivel extremadamente bajo de arsénico en algunas muestras -SB SN2, SB SN-6 y sB SN-7-, ya que los minerales de este yacimiento se han caracterizado tradicionalmente por un alto nivel de As, siendo tan bajos como en algunas de las publicadas por Escanilla (2016), muestras CMO7, CMII y CM12.

Co y Ni se han considerado como los elementos más característicos de las mineralizaciones de Cerro Minado (Favreau et al., 2013; Delgado et al., 2014: 17; Murillo et al., 2017: 7). Si bien la presencia de $\mathrm{Ni}$ se mantiene en toda la muestra $-0,39 \%$ 


\begin{tabular}{|c|c|c|c|c|c|c|c|c|c|c|c|c|c|c|c|}
\hline NUM-ANS & TIPO & $\mathrm{N} \cdot{ }^{0} \mathrm{INV}$ & $\mathrm{Fe}$ & $\mathrm{Ni}$ & $\mathrm{Cu}$ & $\mathrm{Zn}$ & As & $\mathrm{Ag}$ & Sb & $\mathrm{Pb}$ & $\mathrm{Bi}$ & $\mathrm{Ti}$ & Mn & Co & OTROS ELEM. \\
\hline PA25245 & vasija reducción & новв-91-с25-155 & 4,94 & 0,06 & 0,45 & 0,03 & 0,07 & ND & ND & 0,01 & ND & 0,39 & 0,03 & 0,14 & 93,86 \\
\hline PA25246 & vasija reducción & ноsв- 91 c1/248 & 6,86 & ND & 0,54 & $\mathrm{ND}$ & 0,03 & ND & ND & ND & ND & 0,78 & 0,06 & ND & 91,7 \\
\hline PA25247 & vasija reducción & нозв- 91 c1/399 & 4,99 & ND & 7,76 & 0,12 & 0,64 & ND & ND & 0,01 & 0,01 & 0,24 & nd & ND & 86,21 \\
\hline PA25248 & goterón & SB SN-1 & 3,79 & 0,07 & 89,1 & 0,3 & 6,66 & ND & ND & 0,07 & ND & ND & ND & $\mathrm{ND}$ & ND \\
\hline PA25249 & mineral $\mathrm{Cu}$ & SB SN-2 & 3,26 & 1,16 & 92,0 & 2,07 & 0,89 & ND & ND & ND & ND & ND & ND & 0,66 & ND \\
\hline
\end{tabular}

FIG. 13. Resultados obtenidos mediante FRX; valores expresados en porcentajes sobre peso; material hallado en el yacimiento de Santa Bárbara (HOSB-Huércal-Overa Santa Bárbara).

\begin{tabular}{|c|c|c|c|c|c|c|c|c|c|c|c|c|c|c|c|}
\hline NUM-ANS & TIPO & N. ${ }^{0}$ INV. & $\mathrm{Fe}$ & $\mathrm{Ni}$ & $\mathrm{Cu}$ & $\mathrm{Zn}$ & As & $\mathrm{Ag}$ & $\mathrm{Sb}$ & $\mathrm{Pb}$ & $\mathrm{Bi}$ & $\mathrm{Ti}$ & Mn & Co & OTROS ELEM. \\
\hline PA25250 & mineral $\mathrm{Cu}$ & $\begin{array}{l}\text { Cerro Minado } \\
\text { SB SN }-3\end{array}$ & 17,2 & ND & 51,6 & 0,67 & 29,8 & ND & 0,34 & 0,07 & 0,28 & ND & ND & ND & ND \\
\hline PA25250B & mineral $\mathrm{Cu}$ & $\begin{array}{l}\text { Cerro Minado } \\
\text { SB SN }-3\end{array}$ & 23,8 & ND & 46,8 & 0,49 & 27,7 & ND & 0,76 & 0,2 & 0,22 & ND & $\mathrm{ND}$ & ND & $\mathrm{ND}$ \\
\hline PA25251 & mineral $\mathrm{Cu}$ & $\begin{array}{l}\text { Cerro Minado } \\
\text { SB SN }-4\end{array}$ & 6,32 & 0,42 & 82,3 & 0,55 & 9,94 & ND & ND & 0,06 & 0,18 & ND & ND & 0,2 & ND \\
\hline PA25252 & mineral $\mathrm{Cu}$ azul & $\begin{array}{l}\text { Cerro Minado } \\
\text { SB SN }-5\end{array}$ & 1,36 & 0,45 & 85,5 & 1,49 & 10,1 & ND & $\mathrm{ND}$ & $\mathrm{ND}$ & ND & ND & ND & 0,3 & ND \\
\hline PA25253 & mineral $\mathrm{Cu}$ verde & $\begin{array}{l}\text { Cerro Minado } \\
\text { SB SN }-6\end{array}$ & 0,98 & 0,17 & 30,0 & 0,51 & 0,14 & ND & ND & ND & ND & ND & ND & ND & 68,09 \\
\hline PA25254 & mineral $\mathrm{Cu}$ azul & $\begin{array}{l}\text { Cerro Minado } \\
\text { SB SN-7 }\end{array}$ & 1,48 & 0,08 & 9,03 & ND & 0,12 & ND & ND & ND & ND & $\mathrm{ND}$ & ND & ND & 89,25 \\
\hline
\end{tabular}

FIG. 14. Resultados obtenidos mediante FRX; valores expresados en porcentajes sobre peso; las muestras han sido tomadas en las escombreras de la cantera de la cima de Cerro Minado.

de media-, con la excepción de la muestra 3, el Co $-0,38 \%$ de media- solo se ha detectado en tres de las siete muestras analizadas (Montero, 1992: 151153, tabs.; Delgado et al., 2014: 19; Escanilla y Delgado, 2015: 95-96, tabs. 4-5; Escanilla, 2016: 132, tab. 3.12) ${ }^{8}$.

En cuanto a los restos de vasijas de reducción se refiere, los análisis se realizaron sobre unas finas capas de escorificación adheridas a la superficie de las cerámicas. La presencia de As es consistente en los tres análisis, lo cual indica un uso de minerales de cobre arsenicados, aunque convendría realizar otros tipos de análisis, tales como DRX o SEM-EDX, para determinar la relación $\mathrm{Cu}$-As de estos minerales usados en el proceso metalúrgico.

8 Montero, op. cit. n. 3.
Pese a la variabilidad de las mineralizaciones de Cerro Minado, en el caso de la muestra HOSB91-c25-155 la presencia de As-Co-Ni parece relacionarlo directamente a la reducción de minerales pertenecientes a esta mina, aunque existen en el valle del Almanzora mineralizaciones similares en Oria o Tíjola. Es importante resaltar los niveles relativamente bajos de As presentes en los restos escorificados de las vasijas. Los niveles bajos de As se pueden deber tanto a la baja concentración de este elemento en los minerales usados durante el proceso metalúrgico en sí o bien al proceso metalúrgico, ya sea reducción o fundición, pudiendo quedar menos concentraciones de As en las escorificaciones durante el proceso de reducción.

Finalmente, cabe mencionar el resultado obtenido del goterón de fundición -SB SN-1-. Primero, 


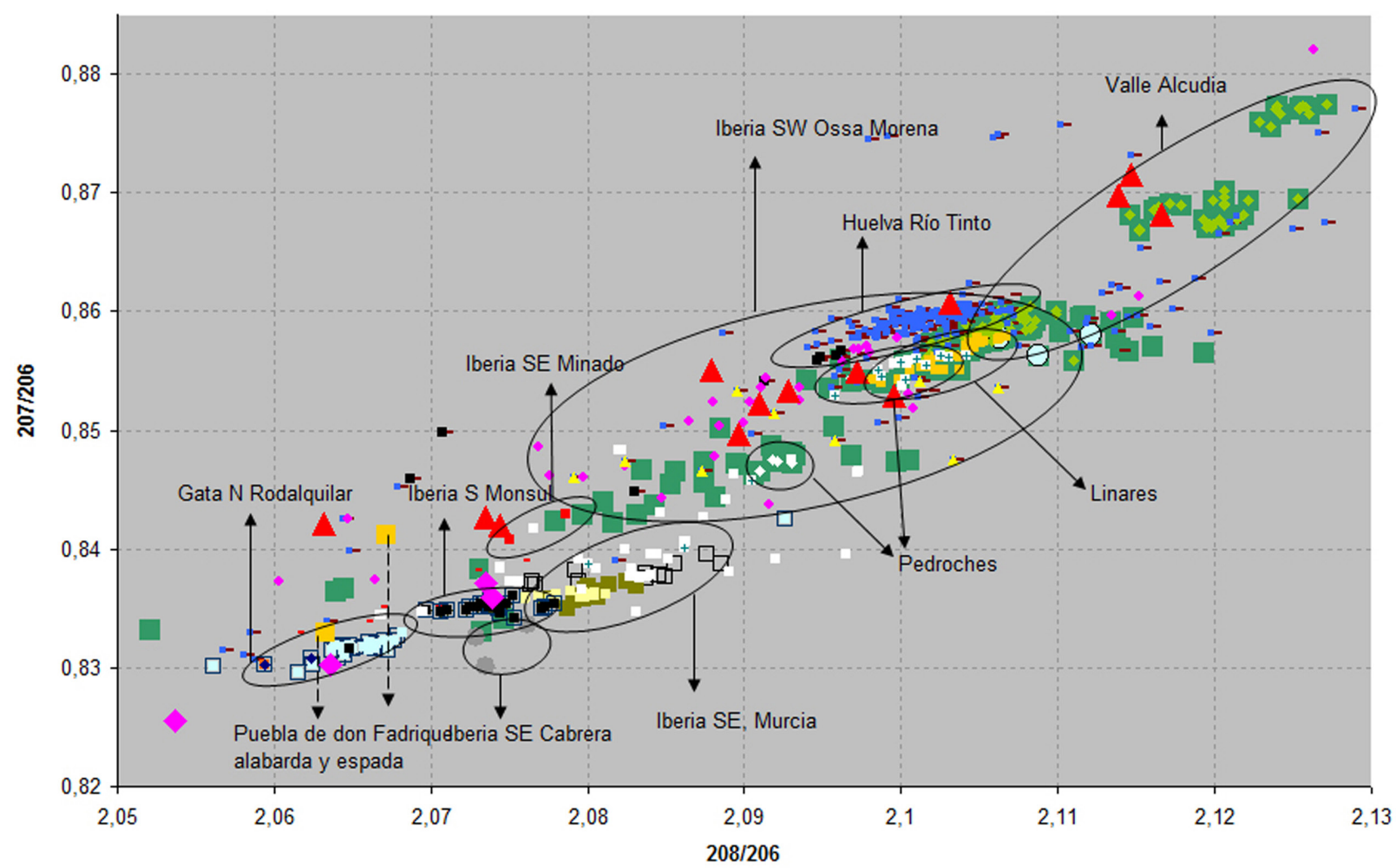

Fig. 15. Posición de Cerro Minado entre las mineralizaciones de Andalucía según los análisis de isótopos de plomo. Valle Alcudia (cuadrado verde oscuro con punto verde claro); Iberia so Ossa Morena (cuadrado verde); Pedroches (cuadrados verdes con punto blanco); Huelva Río Tinto (pequeños cuadrados azules); Linares (cuadrados naranjas); Iberia SE Murcia MazarrónCartagena (cuadrados verde-amarillo y cuadro sin relleno); Iberia SE Sierra Cabrera (puntos grises); Iberia SE Minado (cuadrados rojos pequeños); Iberia SE Sierra de Gata Monsul (cuadrado negro); y Gata N Rodalquilar (azul claro).

hemos de señalar el alto contenido de As comparado con los restos analizados de las vasijas. Pese a que las vasijas parecen relacionarse más con minerales de un contenido relativamente bajo de As, siempre teniendo en cuenta la volatilidad de este elemento, dependiendo en gran medida de las condiciones redox de la reducción mineral, en el caso del goterón parece ser lo contrario. Si unimos este hecho a la alta variabilidad de la composición de los minerales de Cerro Minado, esto puede indicar un uso relativamente aleatorio de las mineralizaciones. Es decir, que, aunque busquen unos minerales de unas características parecidas, no parece que exploten unos filones concretos y abandonen otros solo porque no se ajuste a lo que quieren, sino más bien que aprovechan lo que les sea más fácil obtener, aunque a esta propuesta aún le falta ser respaldada por más análisis de restos de producción procedentes del yacimiento, para poder establecer si existió o no una selección de un tipo de mineral frente a otro, además de la ampliación en cuanto a tipos de análisis que nos ayuden a esclarecer los distintos procesos metalúrgicos que fueron llevados a cabo en el poblado.

Sea cual fuere el caso, los resultados obtenidos vienen a ratificar, en general, los datos obtenidos previamente acerca de las mineralizaciones de Cerro Minado y su posible vinculación con la producción metalúrgica en el yacimiento de Santa Bárbara.

Aunque varios equipos han realizado muestreos de las minas de Cerro Minado para su mejor caracterización isotópica' ${ }^{9}$, actualmente los únicos datos publicados corresponden a un primer muestreo realizado por el equipo de la Univ. de Oxford

9 Com. pers. de Montero y Risch. 


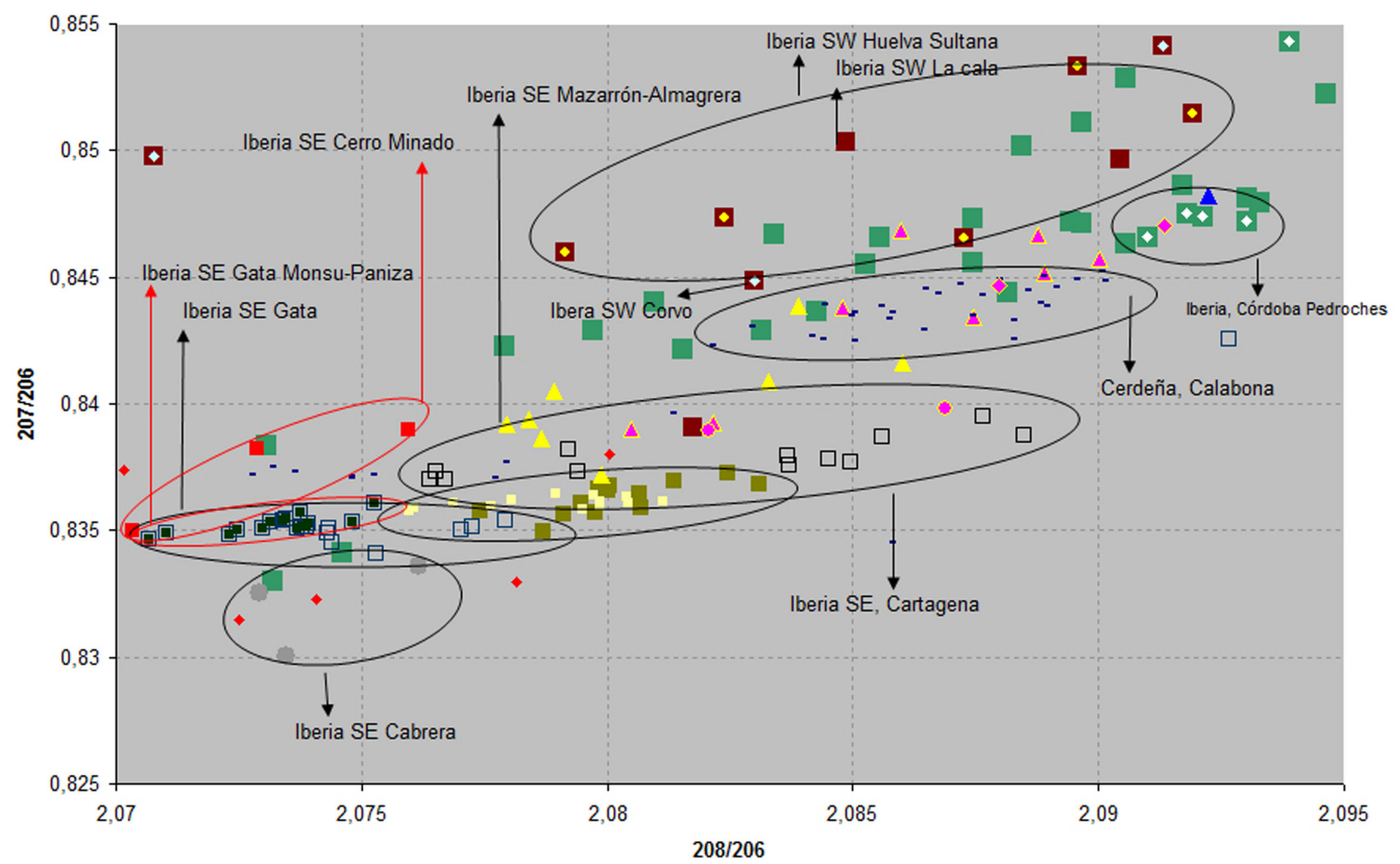

FIG. 16. Posición de Cerro Minado entre las mineralizaciones del SE ibérico según los análisis de isótopos de plomo. Iberia SO Huelva Sultana (cuadrados marrones con punto amarillo); Iberia Córdoba Pedroches (cuadrados verdes con punto blanco); Cerdeña Calabona (rectángulos pequeños azules); Iberia SE Cartagena (cuadrados grises sin relleno); Iberia SE Mazarrón-Almagrera (cuadrados verde-amarillo); Iberia SE Cerro Minado (cuadrados rojos); Iberia SE Sierra Cabrera (puntos grises); e Iberia SE Gata y Gata Monzu-Paniza (cuadrados negros y cuadrados azules sin relleno).

en colaboración con la Univ. Autónoma de Barcelona (Stos-Gale et al., 1999: muestras sP55 y 57), que hemos representado con los isótopos de plomo 207/206 y 208/206 a dos escalas, 2.07-2.095 y 2.05-2.13, para facilitar su comparación con otros grupos del s de la Península Ibérica (Figs. 15 y 16). En ambos gráficos se puede apreciar que Cerro Minado se individualiza con relativa claridad de otras áreas grandes mineras, tanto del SE como Sierra Cabrera (Almería), Sierra Almagrera-Mazarrón (Almería-Murcia) y Cartagena (Murcia), como de Andalucía centro-oriental y centro-occidental, caso de Linares (Jaén) y Pedroches (Córdoba). Eso mismo sucede respecto a Andalucía Occidental, el grupo de Riotinto (Hueva) y la región geológica de Ossa Morena en Huelva con su proyección hacia el s de Portugal.
En todo caso, creemos que los límites del campo isotópico Cerro Minado deben definirse con más precisión. Como artefactos procedentes de esta mineralización se han sugerido una espada de cinco remaches de El Argar, la muestra AM 18, sin descartar como alternativa Calabona en Cerdeña (Stos-Gale, 2001: 450, tab. 2, 452), que parecen seguir en el caso de Cerro Minado, con prudencia, Montero y Murillo (2010: 46, fig. 6). También se ha vinculado con la mineralización un puñal de tres remaches de La Bastida de Totana, la muestra MU 15, igualmente sin descartar como alternativa Calabona en Cerdeña (Stos-Gale, 2001: 450, tab. 2, 452), mientras Montero y Murillo enfatizan su proximidad con un goterón de cobre de Terrera Ventura (Tabernas, Almería); y la muestra AM 9, donde nuevamente Stos-Gale (2001: 450, tab. 2, 452) 
propone tanto Cerro Minado como Calabona en Cerdeña. Finalmente, de un hacha de Fuente Álamo, fa 13, Stos-Gale (2001: 450, tab. 2, 454) sugiere un origen en metal sardo de Calabona, mientras Montero y Murillo (2010: 44, tab. 1; 46, fig. 6) enfatizan su proximidad con dos muestras de mineral parcialmente reducido de Almizaraque, las cuales están relativamente cerca de una de las dos muestras de Cerro Minado. En conclusión, los datos actuales sugieren provisionalmente un aprovisionamiento a yacimientos inmediatos tanto en el Calcolítico como podría ser Almizarque, como durante el Bronce Inicial y Medio, hacia Fuente Álamo en la cuenca del Bajo Almanzora, El Argar en la cuenca baja del río Antas y La Bastida en la cuenca murciana del río Guadalentín. Merece destacarse también el bajo porcentaje de estaño de estos artefactos argáricos, el 1,11\% en el puñal de La Bastida o el 1,24\% en el hacha de Fuente Álamo.

\section{Conclusiones}

El poblado de Puente de Santa Bárbara parece surgir en un momento avanzado del Calcolítico Medio, con los datos actualmente disponibles, y está dentro de un eje de yacimientos fortificados próximos al cauce del río Almanzora que forman Almizaraque (Cuevas del Almanzora) (Delibes et al., 1986a), que consideramos el poblado central de la comarca del Bajo Almanzora; Zájara (Camalich et al., 1992); Campos (Cuevas del Almanzora) (Martín Socas et al., 1985-86); Puente de Santa Bárbara (Huércal-Overa) (González Quintero et al., 1993); y probablemente también La Cueva 3 (Arboleas) ${ }^{10}$ (Martín Socas et al., 1999: 394, fig. 85). De ellos, solo Almizaraque y Puente de Santa Bárbara tienen clara continuidad durante el Calcolítico Final por la presencia de cerámica campaniforme

10 Mederos, A.: Los Estados Incipientes del Sureste de la Península Ibérica. Repercusiones en las cuencas de los rios Aguas, Antas y Almanzora. Almería (4500-1300 a. C.153001600 a. C.). Tesis doctoral defendida en 1993/94 en la Univ. de La Laguna (disponible en ftp://tesis.bbtk.ull.es/ ccssyhum/cs23.pdf).
(Delibes et al., 1986a: 171; González Quintero et al., 1993: 29, 28 fot.). No sucede así en Campos que parece ser destruido en la transición al Calcolítico Final, periodo que abarca entre c. 2475-2275 cal AC en el SE, pues de un enterramiento adulto femenino amortizando la parte superior del silo 3, en el corte 9, se obtuvo una datación de c. 2590-2490 cal AC y la destrucción de la estructura fortificada según su nivel de incendio indica c. 2475 cal AC (Martín Socas et al., 1985-87: 137; Mederos, 1995: 56). Hernando (1988: 588, 637; 1988a: 186, 191, 195) ${ }^{11}$ sugirió identificar como cerámicas campaniformes tipo Ciempozuelos dos fragmentos incisos de la 'casa' c (Siret y Siret, 1890: lám. 10/77-78). Uno de ellos solo presenta dos líneas horizontales en zigzag, incisas o impresas con matriz dentada, pero carece de pasta blanca. El segundo, que sí se ha "rellenado con una sustancia [...] blanca o negra, según los sitios...", presentaría seis líneas en zigzag dispuestas a intervalos regulares dentro de una banda incisa que las enmarca, en una forma cerámica de tendencia troncocónica invertida. Ambos no responden a un patrón decorativo tipo Ciempozuelos o Campaniforme del Sudeste.

El carácter de poblado amurallado de Santa Bárbara, con presencia de bastiones semicirculares, encuentra paralelos en otros yacimientos del cauce del río Almanzora como Campos (Siret y Siret, 1890: lám. 9; Camalich et al., 1998: 402-403, fig. 5) o Almizaraque (Delibes et al., 1986b: taf. 1b), poblado fortificado que conserva incluso un bastión semicircular, a pesar de las dudas iniciales por estar afectadas algunas de estas estructuras por las excavaciones previas de Luis Siret (Delibes et al., 1986a: 170, 173, 176).

Durante el Calcolítico Medio, a partir del 3100 cal AC, parece apreciarse una intensificación de la producción metalúrgica por el incremento del número de artefactos de cobre en los yacimientos. No obstante, a pesar de la cercanía del Cerro de la Virtud (Cuevas del Almanzora) con la antigua

11 Hernando Gonzalo, A.: Evolución interna y factores ambientales en la interpretación del Calcolitico del sureste de la Península Ibérica. Una revisión critica. Tesis doctoral defendida en 1988 en la Univ. Complutense de Madrid. 
mina de la Virtud de San José12, cerro en el que se localizaron niveles del Calcolítico Medio (Montero y Ruiz Taboada, 1999: 13) y del Calcolítico Final con cerámica campaniforme del grupo del Sudeste (Garrido, 1996: 65, fig. 2), el sondeo realizado en el Cerro de la Virtud resultó insuficiente para poder valorar posibles actividades metalúrgicas.

La presencia de óxidos de cobre, del tipo de la malaquita y cuprita en Sierra Almagro, tuvo su punto de explotación en el yacimiento calcolítico del Puente de Santa Bárbara, con la presencia de dichos minerales en bruto, escorias parcialmente procesadas, nodulillos de cobre, vasijas de reducción y crisoles. Los análisis sugieren que la presumible principal fuente de abastecimiento se encontraría a tres kilómetros en dirección Noreste, en el Cerro Minado, donde abundan dichas mineralizaciones, y cuyo acceso no tendría excesivas dificultades, valiéndose bien de la Rambla de Santa Bárbara, o bien de la Rambla de la Ermita, siendo corroborado el aprovechamiento pretérito de la mencionada mina a través de algunos indicios como la presencia de picos y percutores con marcas de entalle para su enmangue, fechado al menos a inicios del Calcolítico Final, c. 24692336 cal AC (Delgado et al., 2014: 30). Es posible que Cerro Minado, por la presencia de arseniatos, también abasteciese a poblados de la llanura de Lorca como Agua Amarga, donde eran fundidos junto a carbonatos y minerales ferrocupríferos con ganga de sílice libres de arsénico, obtenidos en depósitos locales de cobre (Escanilla et al., 2016: 20 y 26; Escanilla, 2016: 356-358).

La importancia del yacimiento del Puente de Santa Bárbara es que nos encontramos con un asentamiento de dimensiones modestas, 1,5 ha, donde el porcentaje de evidencias metalúrgicas solo podría equipararse en el sudeste de la Península Ibérica a los existentes en Parazuelos (Lorca, Murcia), donde se recogieron $10 \mathrm{~kg}$ de mineral junto a la tumba 1 y otros $10 \mathrm{~kg}$ de escorias en la colina oeste asignables al Calcolítico Medio-Final (Siret y Siret, 1890: 269-272, tab. 1; Escanilla, 2016: 283-284); y Agua

12 Montero, op. cit. n. 3: 166-167, 168, fig. 14.
Amarga (Lorca, Murcia), donde observaron varios kilogramos de escorias del Calcolítico Medio, conservándose en el Museo Arqueológico de Murcia 61 escorias con un peso de $0,48 \mathrm{~kg}$, más otros $109 \mathrm{~g}$ recuperados por Escanilla (2016: 294-295; Escanilla et al., 2016: 13-16). Otros yacimientos contemporáneos como La Ciñuela (Mazarrón, Murcia), que presenta una fase del Calcolítico Medio avanzado y otra del Calcolítico Final con cerámica campaniforme (Ayala e Idáñez, 1987: 287; Mederos, 1995: 61), cuenta con un registro de escorias y vasijas de reducción mucho más modesto (Escanilla, 2016: 299, fig. 5.18 y 19). Por otra parte, Santa Bárbara permite presentar también por primera vez una distribución espacial detallada de los fragmentos de vasijas de reducción y crisoles dentro de un yacimiento calcolítico en el SE. Concretamente, en los tres sectores objeto de excavación, y todos, con claridad, señalan su generalización dentro del hábitat.

El número de artefactos metálicos de cobre es pequeño, solo un punzón y una aguja, pero otros yacimientos del entorno con excavaciones más intensivas como Almizaraque han proporcionado hasta 70 artefactos (Siret, 1948: 117) y 15 más en las excavaciones entre 1980 y 1984 de Delibes y Fernández-Miranda ${ }^{13}$, lo que nos indica que muchos de estos artefactos se encuentran en los poblados más importantes o en los yacimientos centralizadores de cada comarca, como fue el caso de Almizaraque para el Bajo Almanzora, en la actualidad parcialmente enterrado por procesos sedimentarios, siendo solo visible la parte más elevada del mismo, funcionando otros yacimientos como Santa Bárbara como asentamientos destinados a la transformación de materias primas, en este caso metalúrgica.

Estos asentamientos centrales debieron de tener un abastecimiento más diversificado, pues el análisis de los elementos traza muestra que Almizaraque ya no dependía de un abastecimiento del metal desde el inmediato asentamiento en el Cerro de la Virtud y las mineralizaciones de Herrerías, con notables valores de plomo, que apenas está presente en dos fragmentos de vasijas de reducción y en uno de

13 Montero, op. cit. n. 3: 195. 
mineral entre el centenar de muestras analizadas de Almizaraque (Montero, 1999: 339; Müller et al., 2004: 51). Por otra parte, se podrían identificar tres tipos de procedencias metálicas a partir del análisis de los nódulos de escorias de cobre (Müller et al., 2004: 44-45, tab. 6), o cinco posibles mineralizaciones en el poblado de Las Pilas (Murillo et al., 2017: 31).

Un yacimiento intensamente excavado como Campos, después de las campañas de los hermanos Siret y de las más recientes realizadas entre 1976-77 y 1985-86, dirigidas por Camalich y Martín Socas, han aportado 11 punzones, 6 cinceles, 2 hachas y 1 puñal (Siret y Siret, 1890: 76-79; Martín Socas y Camalich, 1986: 189) ${ }^{14}, 20$ artefactos en total.

Otro asentamiento donde la función de control del territorio es más evidente por su emplazamiento más elevado en una meseta aislada topográficamente, Zájara, en cambio, solo cuenta con 1 punzón, 1 hacha plana, 1 puñal y 1 anillo procedentes de las excavaciones de Siret ${ }^{15}$, que marca parámetros similares a Puente de Santa Bárbara. También se localizó un fragmento de brazalete metálico en la campaña de 1990 (Camalich et al., 1992: 208, fig. 5a), después clasificado como un fragmento de punzón, además de unos 60 pequeños nódulos de escorias de cobre en una de las estructuras excavadas en el suelo (Camalich et al., 1998: 267, 105, fig. 47/3).

La conclusión final es plantear, como hipótesis de trabajo, si ya en el Calcolítico Final pudieron surgir asentamientos especializados en la producción de útiles de cobre de acuerdo con la distribución espacial de los elementos vinculados con la metalurgia en la mayor parte de la superficie excavada del yacimiento del Puente de Santa Bárbara, a pesar de las lógicas dudas planteadas por Lull et al. (2010b: 331) para el Calcolítico, que complementaría a su función de control del territorio en un punto clave de cruce de rutas y al aprovechamiento agropecuario del entorno inmediato. Esta especialización en un poblado calcolítico tal vez lo tenga un poblado también pequeño como Agua Amarga (Lorca, Murcia), de 0,25 ha, o más probablemente

14 Montero, op. cit. n. 3: 194.

15 Montero, op. cit. n. 3: 197.
Parazuelos (Mazarrón, Murcia), según sugiere Escanilla (2016: 293, fig. 5.11, 320), aunque haría falta excavaciones para su definitiva confirmación.

Este proceso se aceleró durante la Edad del Bronce, pues solo en el poblado de Peńalosa (Baños de la Encina, Jaén) se han localizado un porcentaje importante de escorias metalúrgicas con unos 150 nódulos de escorias de cobre (Moreno et al., 2010: 310 ), a los que se suma todo un vertedero de escorias en la parte superior de la ladera sur (Contreras y Moreno, 2015: 52). Las evidencias procedentes de La Bastida (Totana, Murcia) son una concentración de 70 pequeños nódulos de escorias que suman $2 \mathrm{~g}$ localizados en los niveles iniciales de la entrada de la muralla (Lull et al., 2014: 562, fig. 3, 565; Escanilla, 2016: 314-315, fig. 5.24), pero son más conocidas otras de minerales de plomo. Inicialmente se creía que procedían de niveles del Bronce Tardío (Lull et al., 2010a: 25 y 2010b: 333), aunque recientes estudios analíticos las identifican como escorias de colada producto de la reducción de la galena, con porcentajes de plomo del 5 al 22\% y una media del $10-11 \%$, similar a las escorias de plomo de época romana en Cartagena (Lull et al., 2014: 562, fig. 3; 565; Escanilla, 2016: 312-313, fig. 5.22, tab. 5.4). Queda la duda sobre los nódulos de escorias procedentes de El Oficio (Cuevas del Almanzora, Almería) (Siret y Siret, 1890: 160, lám. 62/52), donde algunos son exclusivamente plomo fundido (Siret y Siret, 1890: 160, lám. 62/50-51) y las de El Argar (Antas, Almería) (Siret y Siret, 1890: 160, lám. 27/16-17), pues ambos también presentan esta fase postargárica e islámica en el último caso.

Por ello, con los datos actualmente disponibles, es precisamente Peñalosa el único poblado comparable a Puente de Santa Bárbara, pero ya durante el Bronce Medio avanzado, al presentar evidencias de actividades metalúrgicas en la mayor parte de las unidades habitacionales del poblado (Moreno, 2000; Moreno et al., 2010: 320; Lull et al., 2010b: 334, tab. 2, 335; Moreno, Alarcón y Contreras, 2012: 105-106, fig. 5; Contreras y Moreno, 2015: 48-54, lám. 15-21). No obstante, esto no implica en ambos casos su carácter exclusivo o excepcional, sino que es lo que actualmente podemos inferir 
para el sudeste respecto a los poblados excavados. En otros casos que hemos mencionado para el Calcolítico, caso de Parazuelos con c. $10 \mathrm{~kg}$ de escorias por tratarse de una excavación de fines del s. XIX con una recuperación parcial del registro metalúrgico, u otros aún no excavados como Agua Amarga, pueden responder a una misma especialización y abastecer también a las redes de intercambio dentro del sudeste, con una producción que superaba el ámbito de autosuficiencia del propio poblado, algo que ya tenemos confirmado durante el Bronce Argárico.

\section{Bibliografía}

Arribas, A.; Molina, F.; Carrión, F.; Contreras, F.; Martínez Fernández, G.; Ramos, A.; Sáez, L.; De la Torre, F.; Blanco, I. y Martínez, J. (1987): "Informe preliminar de los resultados obtenidos durante la vi campańa de excavaciones en el poblado de Los Millares (Santa Fe de Mondújar, Almería). 1985". En Anuario Arqueológico de Andalucía 1985. II. Actividades sistemáticas. Sevilla: Junta de Andalucía, pp. 245-262.

Arribas, A.; Molina González, F.; De la Torre, F.; Nájera, T. y SÁez, L. (1978): "El poblado de la Edad del Cobre de El Malagón (Cúllar-Baza, Granada). Campaña de 1975”, Cuadernos de Prehistoria de la Univ. de Granada, 3, pp. 67-116.

Ayala, M. a M. e IdÁŃEz, J. F. (1987): "El yacimiento argárico de 'El Rincón', Almendricos (Lorca, Murcia) y su datación cronológica según el C-14". En XVIII Congreso Nacional de Arqueología (Las Palmas-Tenerife, 1985). Zaragoza, pp. 349-361.

Camalich, M. a D.; Martín Socas, D.; González Quintero, P.; Chávez, E.; Afonso, J.; Aramburu, E.; Buxó, R.; Díaz, A.; Echallier, J.; Goñi, A.; Hernández, J.; López, J.; Martínez, G.; Mederos, A.; Morales, R.; Paz, M.; Pérez, V.; RodríGuez, M.a; Rodríguez, A. y SÁnchez, A. (1998): El territorio almeriense desde los inicios de la producción hasta fines de la Antigüedad. Un modelo: la Depresión de Vera y Cuenca del Rio Almanzora. Arqueología Monografías. Sevilla: Junta de Andalucía.

Camalich, M. a D.; Martín Socas, D.; Mederos, A.; González Quintero, P.; Díaz Cantón, A. A. y López Salmerón, J. J. (1992): “Informe provisional de los trabajos de excavación realizados en el poblado de Zájara (Cuevas del Almanzora, Almería). Campaña de 1990”. En Anuario Arqueológico de Andalucia 1990. II. Actividades sistemáticas. Sevilla: Junta de Andalucía, pp. 205-209.

Contreras, F. y Moreno, A. (2015): “Minería y metalurgia del cobre entre las poblaciones argáricas. La aportación del poblado de Peñalosa”. En López Ballesta, J. M. (ed.): Phicaria. ilit. Minería y metalurgia en el Mediterráneo y su periferia oceánica. Mazarrón-Murcia: Univ. Popular de Mazarrón, pp. 38-58.

Cortés, H. (2007): "El papel de los elementos cerámicos en los procesos metalúrgicos. El caso de Peńalosa, grupo estructural vi", Arqueología y Territorio, 4, pp. 47-69.

Delgado, S.; Escanilla, N. y Risch, R. (2014): "Mazas ocultas. Rastros de minería prehistórica en el cerro minado de Huércal-Overa (Almería)", Cuadernos de Prehistoria de la Univ. de Granada, 24, pp. 13-44.

Delibes, G.; Fernández-Miranda, M.; Fernández-Posse, M. a D. y Martín Morales, C. (1986a): "El poblado de Almizaraque". En Homenaje a Luis Siret 1934-1984 (Cuevas del Almanzora, 1984). Sevilla: Junta de Andalucía, pp. 167-177.

Delibes, G.; Fernández-Miranda, M.; Fernández-Posse, M. a D. y Martín Morales, C. (1986b): "Die kupferzeitliche Siedlung von Almizaraque (Cuevas del Almanzora, prov. Almeria)", Madrider Mitteilungen, 26, pp. 11-26.

Domergue, C. (1987): Catalogue des mines et des fonderies antiques de la Péninsule Ibérique. Madrid: Public. Casa de Velázquez.

Escanilla, N.; Bourgarit, D. y Mille, B. (2016): "Mezcla de minerales y cobre arsenical durante el Calcolítico. El excepcional caso de Agua Amarga (La Fuensanta, Lorca)", Alberca, 14, pp. 7-30.

Escanilla, N. y Delgado, S. (2015): "Minería prehistórica del cobre (3100-1550 cal ANE) en el Levante murciano”. En López Ballesta, J. M. (ed.): PhicaRIA. III. Minería y metalurgia en el Mediterráneo y su periferia oceánica. Mazarrón-Murcia: Univ. Popular de Mazarrón, pp. 78-99.

Favreau, G.; Eytier, C.; Eytier, J. R. y Escanilla, N. (2013): "Les mines de Cerro Minado, Huércal-Overa (Almería, Espagne)", Les Cahier de Micromonteurs, 121 (3), pp. 1-122.

Garrido, R. (1996): "Redes de intercambio entre el Sureste y el País Valenciano durante el Calcolítico. Reflexiones en torno a un patrón decorativo campaniforme", Complutum, 7, pp. 63-72. 
González Quintero, P.; Díaz Cantón, A. A.; Camalich, M. ${ }^{a}$ D.; Martín Socas, D.; Mederos, A. y López Salmerón, J. J. (1992): "Prospección arqueológica superficial en la Cuenca del río Almanzora (Almería). Informe provisional de la campaña de 1990". En Anuario Arqueológico de Andalucia, 1990. Vol. II. Actividades sistemáticas. Sevilla: Junta de Andalucía, pp. 59-63.

González Quintero, P.; Mederos, A.; Díaz Cantón, A. A.; Martín Socas, D.; Camalich, M. a D. y López Salmerón, J. J. (1993): "El poblado fortificado de la Edad del Cobre del Puente de Santa Bárbara (Almería)”, Vegueta, 1, pp. 21-30.

Hernando, A. (1988): “¿Evolución cultural diferencial del Calcolítico entre las zonas áridas y húmedas del Sureste español?", Trabajos de Prehistoria, 44, pp. 171-200.

Lull, V.; Micó, R.; Rinuete, C. y Risch, R. (2010a): "Las relaciones políticas y económicas de El Argar", Menga, 1, pp. 10-35 y 212-224.

Lull, V.; Micó, R.; Rinuete, C. y Risch, R. (2010b): "Metal and social relations of production in the $3^{\text {rd }}$ and $2^{\text {nd }}$ millennia $\mathrm{BC}$ in the southeast of the Iberian Peninsula", Trabajos de Prehistoria, 67 (2), pp. 323-347.

Lull, V.; Micó, R.; Rinuete, C. y Risch, R. (2014): "The social value of silver in El Argar". En Meller, H.; Risch, R. y Pernicka, E. (eds.): Metalle der Macht-Frühes Gold und Silber/Metals of power-Early gold and silver (Halle, 2013). Tagungen des Landesmuseums für Vorgeschichte Halle, 11. Halle, pp. 557-575.

Martín Socas, D. y Camalich, M.a D. (1986): “Las excavaciones en el poblado de Campos (Cuevas del Almanzora, Almería) y su problemática”. En Homenaje a Luis Siret 1934-1984 (Cuevas del Almanzora, 1984). Sevilla: Junta de Andalucía, pp. 178-191.

Martín Socas, D.; Camalich, M.a D.; González Quintero, P.; Meneses, M.a D. y Mederos, A. (1985-87): "El poblado de Campos (Cuevas del Almanzora). Resultado de las campañas de excavación de 1985 y 1986", Tabona, 6, pp. 129-146.

Martín Socas, D.; Mederos, A.; Chávez, E.; Díaz Cantón, A.; Aramburu, E. y López Salmerón, J. (1999): "Estudio del Territorio". En Camalich, M. y Martín Socas, D. (eds.): El territorio almeriense desde los inicios de la producción hasta fines de la Antigüedad. Un modelo: la Depresión de Vera y Cuenca del Río Almanzora. Sevilla: Junta de Andalucía, pp. 137-170.
Mederos, A. (1995): "La cronología absoluta de la prehistoria reciente del sureste de la Península Ibérica”, Pyrenae, 26, pp. 53-90.

Molina, F. (1991): "Proyecto Millares (Los inicios de la metalurgia y el desarrollo de las comunidades del Sudeste de la Península Ibérica durante la Edad del Cobre)". En Anuario Arqueológico de Andalucia 1989. II. Actividades Sistemáticas. Sevilla: Junta de Andalucía, pp. 211-213.

Molina, F. y Arribas, A. (1993): "Millares. (Los inicios de la metalurgia y el desarrollo de las comunidades del Sureste de la Península Ibérica durante la Edad del Cobre)". En Investigaciones Arqueológicas en Andalucía, 1985-1992. Huelva: Junta de Andalucía, pp. 311-316.

Montero, I. (1999): “Sureste”. En Delibes, G. y MonTERO, I. (eds.): Las primeras etapas metalúrgicas en la Península Ibérica. II. Estudios regionales. Madrid: Fundac. Ortega y Gasset-Ministerio de Educación y Cultura, pp. 333-357.

Montero, I. y Murillo, M. (2010): "La producción metalúrgica en las sociedades argáricas y sus implicaciones sociales: una propuesta de investigación", Menga, 1, pp. 37-52.

Montero, I. y Murillo, M. (2014): “Difusión o innovación tecnológica: los inicios de la metalurgia en la Península Ibérica”. En Movilidad, contacto y cambio. II Congreso de Prehistoria de Andalucía (Antequera, 2012). Sevilla: Junta de Andalucía, pp. 65-75.

Montero, I.; Rihuete, C. y Ruiz Taboada, A. (1999): "Precisiones sobre el enterramiento colectivo neolítico del Cerro Virtud (Cuevas de Almanzora, Almería)", Trabajos de Prehistoria, 56 (1), pp. 119-130.

Montero, I. y Rovira, S. (2001): "Estudios de los restos metalúrgicos de Cerro Virtud (Cuevas de Almanzora, Almería)". En Anuario Arqueológico de Andalucía 1997. II. Actividades Sistemáticas. Sevilla: Junta de Andalucía, pp. 30-34.

Montero, I. y Ruiz Taboada, A. (1999): "Informe de la excavación arqueológica de urgencia realizada en el Cerro Virtud de Las Herrerías (Cuevas del Almanzora, Almería)". En Anuario Arqueológico de Andalucía 1994. III. Actividades de Urgencia. Sevilla: Junta de Andalucía, pp. 9-15.

Moreno, M. A. (2000): "La metalurgia de Peñalosa". En Contreras, F. (ed.): Proyecto Peñalosa. Análisis histórico de las comunidades de la Edad del Bronce del piedemonte meridional de Sierra Morena y depresión Linares-Bailén. Arqueología Monografías, 10. Sevilla: Junta de Andalucía, pp. 165-222. 
Moreno, M.a A.; Alarcón, E. y Contreras, F. (2012): "La metalurgia y otras actividades de mantenimiento en una casa argárica. El complejo estructural xvia de Peñalosa (Baños de la Encina, Jaén)", Antiquitas, 24, pp. 95-116.

Moreno, M.a A.; Contreras, F.; Renzi, M.; RoviRA, S. y CorTÉs, H. (2010): "Estudio preliminar de las escorias y escorificaciones del yacimiento metalúrgico de la Edad del Bronce de Peñalosa (Baños de la Encina, Jaén)", Trabajos de Prehistoria, 67 (2), pp. 305-322.

Müller, R.; Golcenberg, G.; Bartelleim, M.; Kunst, M. y Pernicka, E. (2007): "Zambujal and the beginnings of metallurgy in southern Portugal". En La Niece, S.; Hook, D. y Craddock, P. T. (eds.): Metals and mines: studies in archaeometallurgy. London: Archetype Publications Ltd., pp. 15-26.

Müller, R.; Rehren, T. y Rovira, S. (2004): "Almizaraque and the early copper metallurgy of Southeast Spain: new data", Madrider Mitteilungen, 49, pp. 94-114.

Murillo, M.; Martinón, M.; Camalich, M.a D.; Martín Socas, D. y Molina, F. (2017): "Early metallurgy in sE Iberia. The workshop of Las Pilas (Mojácar, Almería, Spain)", Archaeological and Anthropological Sciences. doi: 10.1007/s12520-016-0451-8.

Nocete, F. (2004): Odiel. Proyecto de investigación arqueológica para el análisis del origen de la desigualdad social en el suroeste de la Peninsula Ibérica. Arqueología Monografías. Sevilla: Junta de Andalucía.

Nocete, F.; Queipo de Llano, G.; Sáez, R.; Nieto, J. M.; Inácio, N.; Rodríguez Bayona, M.; Peramo, A.; Vargas, J. M.; Cruz Auñón, R.; Gil, J. I. y SAntos, J. F. (2008): “The smelting quarter of Valencina de la Concepción (Seville, Spain): the specialised copper industry in a political centre of the Guadalquivir valley during the Third Millennium вС (2750-2500 вС)", Journal of Archaeological Science, 35, pp. 717-732.

Ramos, A. (1986): "La explotación de recursos líticos por las comunidades prehistóricas. Un estudio de economía primitiva", Cuadernos de Prehistoria de la Univ. de Granada, 11, pp. 237-271.

Rodríguez Ariza, Maa O. (1998): "Antracología”. En Martín Socas, D. y Camalich, M. D. (eds.): El territorio almeriense desde los inicios de la producción hasta fines de la Antigüedad. Un modelo: la Depresión de Vera y Cuenca del Río Almanzora. Sevilla: Junta de Andalucía, pp. 272-288.

Rovira, S. (1999): "Una propuesta metodológica para el estudio de la metalurgia prehistórica: el caso de Gorny en la región de Kargaly (Orenbug, Rusia)", Trabajos de Prehistoria, 56 (2), pp. 85-113.

Rovira, S. (2004): “Tecnología metalúrgica y cambio cultural en la Prehistoria de la Península Ibérica”, Norba. Revista de Historia, 17, pp. 9-40.

Rovira, S. (2005): "Metalurgia de crisol: la obtención de cobre en la prehistoria de la Península Ibérica", De Re Metallica, 5, pp. 87-94.

Rovira, S. y Ambert, P. (2002): "Les céramiques à réduire le minerai de cuivre : une technique métallurgique utilisée en Ibérie, son extension en France méridionale", Bulletin de la Société Préhistorique Française, 99 (1), pp. 105-126.

Ruiz Taboada, A. y Montero, I. (1999): "Ocupaciones neolíticas en Cerro Virtud: estratigrafía y dataciones". En II Congrés del Neolitic à la Peninsula Ibérica (Valencia, 1999). Saguntum Extra, 2. Valencia: pp. 207-212.

Siret, E. y Siret, L. (1890): Las primeras edades del metal en el Sudeste de España. Resultados obtenidos en las excavaciones hechas por los autores desde 1881 a 1887. Barcelona: Tipografía de Heinrich y Cía.

Siret y Cels, L. (1948): "El tell de Almizaraque y sus problemas", Cuadernos de Historia Primitiva, 3 (2), pp. 117-124.

Stos-Gale, Z. A. (2001): "The development of Spanish metallurgy and copper circulation in Prehistoric Southern Spain”. En Gómez Tubío, B.; Respaldiza, M. A. y Pardo, M. a L. (eds.): III Congreso Nacional de Arqueometría (Sevilla, 1999). Sevilla: Univ. de Sevilla-Fundac. El Monte, pp. 445-456.

Stos-Gale, Z. A.; Hunt, M. y Gale, N. H. (1999): "'Report on the results of the elemental and lead isotope analyses of metal artefacts from Gatas and other archaeological sites in its region, and of copper and lead ores from South-East Spain". En Castro, P. V.; Chapman, R. E.; Gili, S.; Lull, V.; Micó, R.; Rihuete, C.; Risch, R. y Sanahuja, M. ${ }^{a}$ E. (eds.): Proyecto Gatas. 2. La dinámica arqueológica de la ocupación prehistórica. Arqueología Monografías. Sevilla: Junta de Andalucía, pp. 347-358. 